\title{
Kinetic Study of the Pyrolysis and Oxidation of Guaiacol
}

\author{
M. Nowakowska, O. Herbinet, A. Dufour, P.A. Glaude* \\ Laboratoire Réactions et Génie des Procédés, CNRS, Université de Lorraine \\ 1 rue Grandville BP 2045154001 Nancy Cedex, France
}

Corresponding author :

Pierre-Alexandre Glaude

Laboratoire Réactions et Génie des Procédés

1 rue Grandville BP 2045154001 Nancy Cedex,

France

Email:pierre-alexandre.glaude@univ-lorraine.fr 


\begin{abstract}
Guaiacol or 2-methoxy phenol is one of the main primary tar produced during lignin pyrolysis. Tar conversion in the gas phase influences the production of gaseous and condensable products, and is also responsible for $\mathrm{PAH}$ and soot formation during biomass and bio-oil gasification or combustion. Guaiacol pyrolysis and oxidation under stoichiometric conditions were studied in a jet stirred reactor between 623 and $923 \mathrm{~K}$ for a residence time of $2 \mathrm{~s}$ and under a pressure of 800 Torr $(106.7 \mathrm{kPa})$. Speciation was obtained thanks to on-line gas-chromatography using flame ionization detection and mass spectrometry and allowed the quantification of 22 species in pyrolysis and 42 species in oxidation. Decomposition of guaiacol starts at $650 \mathrm{~K}$ and a conversion degree of $50 \%$ is obtained at about $785 \mathrm{~K}$ in pyrolysis and $765 \mathrm{~K}$ in oxidation. The main products of reaction are pyrocatechol $0-\mathrm{HOC}_{6} \mathrm{H}_{4} \mathrm{OH}, \quad$-hydroxybenzaldehyde, methylcatechols and light products, such as methane, carbon monoxide, ethylene, and hydrogen. A detailed kinetic model based on a combustion model for light aromatics and anisole has been extended to guaiacol. Thermochemical data of guaiacol and main products were calculated theoretically at the CBS-QB3 level of theory. The model predicts well the conversion of guaiacol and the formation of the main products. Guaiacol decomposes mainly through a unimolecular $\mathrm{O}-\mathrm{C}$ bond breaking to hydroxy phenoxy and methyl radicals in both pyrolysis and oxidation, but $\mathrm{H}$-atom abstractions are also of importance in the low temperature range of the study. The unimolecular mechanism leads mainly to pyrocatechol and methylcatechols, whereas the chain radical mechanism is responsible for the formation of hydroxybenzaldehyde. As for anisole but in a much lower extent, an early formation of benzene and soot precursors is observed.
\end{abstract}




\section{Introduction}

The optimization of the thermal conversion of biomass is a major environmental and economic concern. Wood and other renewable ligno-cellulosic feedstock are widely used in combustion for energy production, but often in low efficiency devices, which emit large amounts of soot and pollutants ${ }^{1,2}$. More advanced thermal processes are developed, such as gasification, to yield a synthesis gas (syngas, mixture of $\mathrm{CO}$ and $\mathrm{H}_{2}$ ), which can be used in small heating units or for the synthesis of liquid fuels (FisherTropsch or methanol) ${ }^{3}$. During both combustion and gasification processes, a large range of pollutants is formed ${ }^{4}$, such as $\mathrm{NO}_{x}, \mathrm{SO}_{x}$, fly ash and tars. The denomination of tar accounts for a complex mixture of condensable vapors containing hundreds of compounds ${ }^{5}$. These products lead to fouling by condensation on cooler surface or polymerization, coke deposit, and catalyst deactivation in the case of gasification processes. Tar conversion or removal is therefore one of the main challenges for the success of gasification technologies and is extensively studied in gas-phase ${ }^{6-8}$ and in catalytic conversion $^{9,10}$. Three main classes of tars were defined ${ }^{5}$ : primary tars are yielded at low temperature and contains mainly oxygenated, while secondary and tertiary tars are produced at higher temperature by maturation of the primary tars in the gas phase; these latter contain aromatics and polycyclic aromatic hydrocarbons (PAH). The control of the formation and conversion of tar implies the understanding of the involved chemical pathways, and the knowledge of the corresponding kinetic parameters under conditions representative of biomass gasification in fluidized bed or of wood combustion furnaces. A significant fraction of aromatic tars originates from the products of lignin pyrolysis, which is mainly composed of p-hydroxyphenyl, guaiacyl and syringil 
units $^{5,11,12}$. The simplest aromatic compound containing a methoxy function, which is anisole, was studied in a previous work as a surrogate of lignin primary $\operatorname{tar}^{13}$, as a first step in order to unravel the chemistry of methoxy aromatics. Thermal decomposition and stoichiometric oxidation of anisole were studied experimentally and results were modeled by means of a detailed kinetic mechanism. The present study focuses on the reaction of pyrolysis and oxidation of guaiacol, or o-methoxy phenol, which is more representative of lignin pattern and is found in large amounts in tars produced from lignin ${ }^{5,7,14-19}$. This compound is furthermore the most often selected surrogate of lignin primary tars in the literature ${ }^{18,20-23}$.

Up to know, very seldom quantitative studies have focused on guaiacol in well-controlled experiments. In order to investigate the fission of the very fragile $\mathrm{O}-\mathrm{C}$ bond in the methoxy group of guaiacol and subsequent reactions, pyrolysis of guaiacol has been first led by heating a small quantity of liquid reactant in a sealed vessel at moderate temperature ${ }^{24-28}$. The bond dissociation energy was estimated to be as low as $59 \mathrm{kcal} \mathrm{mol}^{-1} \cdot{ }^{29}$ Klein and Virk ${ }^{24}$ investigated the thermal decomposition of guaiacol in a closed vessel for temperatures ranging from 523 up to $873 \mathrm{~K}$ and a residence times from 2 to 40 min. At low conversion of guaiacol, methane, carbon monoxide, pyrocatechol (odihydroxybenzene $\left.0-\mathrm{HOC}_{6} \mathrm{H}_{4} \mathrm{OH}\right)$ and phenol were the only detected products. Solid carbon deposit was observed at high conversion, whereas the selectivity in pyrocatechol decreased compared to other products. Ceylan and Bredenberg ${ }^{25}$ found also pyrocatechol as the major primary product after 120 min of reaction at $618 \mathrm{~K}$, minor products being phenol, o-cresol $0-\mathrm{HOC}_{6} \mathrm{H}_{4} \mathrm{CH}_{3}$, methylcatechols and methylguaiacols. Carbon monoxide, methane and ethane were detected among the gaseous light products. A postulated reaction scheme begins with the fission of the $\mathrm{O}-\mathrm{C}$ bond 
yielding a methyl radical and a 2-hydroxyphenoxy radical. The latter combines then with an $\mathrm{H}$-atom to produce pyrocatechol, while methyl radical leads to methane. The authors proposed also a fission of the C-O bond between the aromatic ring and the methoxy group, which produces a 2-hydroxyphenyl radical, precursor of phenol and cresols. This pathways looks however of little importance considering the high bond dissociation energy involved. Other studies confirmed the role of the initial bond breaking, which leads to a first order kinetic behavior, and the nature of the main products ${ }^{16,26-28}$. This mechanism was confirmed by experiments at very low pressure (1mTorr) over a wider range of temperature, up to $1275 \mathrm{~K}$. The formation of 2-hydroxybenzaldehyde $\mathrm{C}_{6} \mathrm{H}_{4} \mathrm{OHCHO}$ was observed also as a minor product ${ }^{27,28}$. The formation route of this latter starts with an $\mathrm{H}$-atom abstraction from the methoxy group of the guaiacol; the formed $\mathrm{HOC}_{6} \mathrm{H}_{5} \mathrm{OCH}_{2}$ radical isomerizes into 2-hydroxy benzyloxy $\mathrm{HOC}_{6} \mathrm{H}_{5} \mathrm{CH}_{2} \mathrm{O}$ radical, which decomposition yields 2-hydroxybenzaldehyde and an $\mathrm{H}$-atom. More recently, a study ${ }^{30}$ at high temperature, up to $1575 \mathrm{~K}$, involving a low pressure micro flow reactor coupled to on-line mass spectrometry and IR absorption spectroscopy, allowed the investigation of the decomposition channel of primary radicals produced from guaiacol. As shown by former experiments, the initial $\mathrm{O}-\mathrm{C}$ bond breaking in guaiacol produces first a methyl radical and 2-hydroxyphenoxy radical. This latter decomposes at high temperature entirely into $\mathrm{CO}$ and hydroxycyclopentadienyl radical, similarly to the $\mathrm{CO}$ elimination well-known in the case of phenoxy radical. Hydroxycyclopentadienyl radical yields cyclopentadienone by an $\mathrm{H}$-atom elimination. Reactions of the cyclic ketone are uncertain, but $\mathrm{CO}$ eliminations should lead to the formation of acetylene $\mathrm{C}_{2} \mathrm{H}_{2}$ and vinylacetylene $\mathrm{C}_{4} \mathrm{H}_{4}$, which molecular ion are experimentally detected. The authors proposed also a formation pathway to phenol through a bimolecular reaction between 
methyl and hydroxycyclopentadienyl radicals. The combination of these species leads to hydroxymethylcyclopentadiene, which produces phenol after rearrangement. The same team studied in the micro flow reactor the pyrolysis of two major products of guaiacol decomposition: salicylaldehyde (2-hydroxybenzaldehyde) and pyrocatechol. ${ }^{31}$ At high temperature (1200K-1500K) and low pressure, these species react by successive unimolecular eliminations to lead to fulveneketene, which decomposes further into $\mathrm{CO}$ and linear $\mathrm{C}_{5}$ alkynes..

To the best of our knowledge, gas phase oxidation of guaiacol has been studied only in the framework of atmospheric chemistry ${ }^{32-34}$, and no combustion conditions have been investigated. Moreover, there is no detailed kinetic model available. The present study aims at investigating experimentally and theoretically the kinetics of thermal decomposition and oxidation of guaiacol and to predict the formation of intermediates leading to secondary and tertiary tars.

\section{Experimental methods}

Experiments were performed in a jet-stirred reactor operated at constant temperature and pressure. The apparatus has already been used and described in numerous thermal decomposition and oxidation gas phase studies ${ }^{35-39}$. The experimental and analytical methods and procedures are that used for the study of anisole ${ }^{13}$ and are recalled below. The fused silica jet-stirred reactor consists of a sphere of $88 \mathrm{~cm}^{3}$ in which the reaction takes place. The injection cross located at the center ensures the high turbulence of the gas injection. The reactor can be considered as a zero dimensional perfectly stirred reactor with homogenous temperature and composition. The preheater of gas and the 
reactor are heated thanks to Thermocoax resistances controlled by type $K$ thermocouples. The temperature precision is better than $1 \%$. The reaction temperature was checked by another type $\mathrm{K}$ thermocouple set in the injection cross in the center of the reactor.

Liquid guaiacol (Merck, purity 99.5\%) flow rate was controlled thanks to a Coriolis flow controller associated to an evaporator heated to $473 \mathrm{~K}$, in which the reactant was mixed with the carrier gas (helium) and oxygen in the case of oxidation. Gas flow rates were controlled by mass flow controllers, the precision of which is $0.5 \%$. Each experiment was done a second time with argon as carrier gas to enable the quantification of hydrogen. Gases were provided by Messer with a purity of $99.999 \%$ for inert gases, and $99.995 \%$ for oxygen. Experiments were performed under 800 Torr $(106.7 \mathrm{kPa})$ for a residence time of $2 \mathrm{~s}$ in the temperature range $523 \mathrm{~K}-898 \mathrm{~K}$ in pyrolysis and $573-923 \mathrm{~K}$ in oxidation, with steps of $25 \mathrm{~K}$. The inlet concentration of guaiacol was set to $0.5 \% \mathrm{vol}$. in both pyrolysis and oxidation. Oxidation experiments were led in stoichiometric conditions.

Unconverted reactant and products were analyzed on-line by gas chromatographs (GC) connected to the outlet of the reactor by a transfer line, which is heated to avoid any condensation. In order to quantify the whole spectra of products, fours chromatographs have been used. Heavy species involving more than five heavy atoms were analyzed in an Agilent 7890a gas chromatograph fitted with a HP-5 capillary column, a flame ionization detector (FID) and a mass spectrometer for species identification. Lighter species were analyzed using a first GC fitted with a Plot-Q capillary column and a FID, and second one containing a Carbosphere packed column, ensuring a good separation for methane, $\mathrm{C}_{2}$ hydrocarbons, and carbon oxides, a thermal conductivity detector (TCD) 
and a FID. Hydrogen was quantified by TCD using a Perichrome 1250 fitted with a $5 \AA$ molecular sieve. The carrier gas for the experiments was then switched from helium to argon to avoid the superposition of the helium peak with that of $\mathrm{H}_{2}$. Light species were calibrated thanks to gas standards. For aromatics and phenolic compounds, the calibration was made using blends of known composition: benzene, phenol, and cresols in toluene, and guaiacol, methylcresols, pyrocatechol in iso-propanol, which insured the solubility of pyrocatechol. The carbon effective number method ${ }^{40}$ was used in the case of other heavy products. The detection threshold was about $1 \mathrm{ppm}$ for the heaviest species (FID), about $50 \mathrm{ppm}$ for carbon oxides and oxygen (TCD), and $100 \mathrm{ppm}$ for hydrogen. Uncertainty were estimated about $\pm 5 \%$ for major species and hydrocarbons but increase to up to $\pm 25 \%$ for phenolic compounds, such as pyrocatechol or methylcatechols, which adsorb on walls or condensate easily. In pyrolysis, carbon mass balance was better than $97 \%$ up to $848 \mathrm{~K}$, and decreases above because of the uncertainties in the quantification of catechols and heavy products; in oxidation, the mass balance was better than $93 \%$ on the whole range of temperature.

\section{Kinetic modeling}

A detailed kinetic mechanism for the thermal decomposition and oxidation of guaiacol has been developed based on the previous model of reaction of anisole ${ }^{13}$, which includes reactions of aromatics as core mechanism ${ }^{41,42}$. A primary mechanism of guaiacol, i.e. reactions of guaiacol and related free radicals, and sub-mechanisms for products, such as pyrocatechol $0-\mathrm{HOC}_{6} \mathrm{H}_{4} \mathrm{OH}$, methylcatechol, and 2hydroxybenzaldehyde, were written. 120 new reactions involving 17 new species were 
added to the anisole mechanism. Finally, the model contains 1601 reactions involving 233 species. It simulates the formation of all the quantified compounds in pyrolysis and most quantified compounds from the oxidation of guaiacol.

Thermochemical properties of some molecules and radicals present in guaiacol mechanism were not available in the literature and were calculated theoretically. In this study, the CBS-QB3 ${ }^{43}$ level of theory was used for the calculation of electronic energies of species with the Gaussian0944 software. For all the species considered, the enthalpies of formation $\left(\Delta_{\mathrm{f}} \mathrm{H}_{298}^{\circ}\right)$ were estimated using atomization reaction energies ${ }^{45}$. The references for atomization energies of each atom were taken from CODATA database ${ }^{46}$. Entropies at $298 \mathrm{~K}$ and heat capacities as a function of temperature have been calculated from the Gaussian output with statistical thermodynamics relationships implemented in ChemRate ${ }^{47}$. Table 1 summarizes the calculated thermochemical data. The structure of the species is displayed in Supplemental Material. Very little data are available in the literature ${ }^{48}$, but some comparison can be done in the case of pyrocatechol and methylcatechols. The calculated enthalpy of formation of the first one, $-64.99 \mathrm{kcal} \mathrm{mol}^{-1}$, lies in the range of experimental measurements ${ }^{49,50}\left(-63.93 \mathrm{kcal} \mathrm{mol}^{-1}\right.$ and $\left.-65.68 \mathrm{kcal} \mathrm{mol}^{-1}\right)$. Ribeiro Da Silva et al. ${ }^{49}$ proposed heats of formation equal to $71.53 \mathrm{kcal} \mathrm{mol}^{-1}$ and $-71.32 \mathrm{kcal} \mathrm{mol}^{-1}$ for 3- and 4-methylcatechol, respectively, which show a good agreement with calculations, and the same order of stability. However, note that methylcatechols isomers are lumped in one species in the model and assimilated to 4-methylcatechol. 
Table 1. Calculated Heats of Formation, Entropies and Heat Capacities for Species and Intermediates Involved in Guaiacol Decomposition.

\begin{tabular}{|c|c|c|c|c|c|c|c|c|}
\hline & \multirow{2}{*}{$\begin{array}{c}\Delta_{\mathrm{f}} \mathrm{H}_{298}^{\circ} \\
\left(\mathrm{kcal} \mathrm{mol}^{-1}\right)\end{array}$} & \multirow{2}{*}{$\begin{array}{c}\mathrm{S}_{298}^{\circ} \\
\left(\mathrm{cal} \mathrm{mol} \mathrm{mo}^{-1} \mathrm{~K}^{-1}\right)\end{array}$} & \multicolumn{6}{|c|}{$\left.\mathrm{C}_{\mathrm{p}}^{\circ}(\mathrm{T}){ }_{(\mathrm{cal} \mathrm{mol}}{ }^{-1} \mathrm{~K}^{-1}\right)$} \\
\hline & & & $300 \mathrm{~K}$ & $500 \mathrm{~K}$ & $800 \mathrm{~K}$ & $1000 \mathrm{~K}$ & $1500 \mathrm{~K}$ & $2000 \mathrm{~K}$ \\
\hline Guaiacol & -60.58 & 87.36 & 32.99 & 50.26 & 66.57 & 73.36 & 83.26 & 88.70 \\
\hline $\mathrm{OC}_{6} \mathrm{H}_{4} \mathrm{OH}$ & -38.00 & 78.05 & 26.05 & 39.96 & 52.20 & 57.07 & 63.94 & 67.69 \\
\hline Pyrocatechol & -64.99 & 80.58 & 28.76 & 43.13 & 55.79 & 60.91 & 68.40 & 72.58 \\
\hline $\mathrm{OHC}_{6} \mathrm{H}_{4} \mathrm{OCH}_{2}$ & -13.87 & 86.88 & 33.37 & 49.75 & 64.31 & 70.26 & 78.91 & 83.70 \\
\hline $\mathrm{HOC}_{6} \mathrm{H}_{4} \mathrm{CH}_{2} \mathrm{O}$ & -13.05 & 86.86 & 31.69 & 48.66 & 64.07 & 70.33 & 79.20 & 84.01 \\
\hline $\mathrm{C}_{6} \mathrm{H}_{4} \mathrm{OHCHO}$ & -56.99 & 82.29 & 29.29 & 45.20 & 59.78 & 65.69 & 74.02 & 78.53 \\
\hline 3-Methylcatechol & -73.06 & 89.85 & 34.86 & 51.56 & 67.16 & 73.67 & 83.28 & 88.63 \\
\hline 4-Methylcatechol & -72.10 & 91.28 & 34.89 & 51.58 & 67.17 & 73.68 & 83.29 & 88.63 \\
\hline Ethylphenol & -33.63 & 88.93 & 34.75 & 54.17 & 72.89 & 80.83 & 92.51 & 98.96 \\
\hline $\mathrm{OC}_{6} \mathrm{H}_{4} \mathrm{OCH}_{3}$ & -25.62 & 86.39 & 31.63 & 48.00 & 63.44 & 69.80 & 78.88 & 83.81 \\
\hline $\mathrm{HOC}_{6} \mathrm{H}_{3} \mathrm{OCH}_{3}$ & -46.27 & 86.81 & 32.16 & 48.44 & 63.60 & 69.85 & 78.84 & 83.74 \\
\hline $\mathrm{OC}_{6} \mathrm{H}_{3} \mathrm{OHCH}$ & -46.99 & 87.98 & 32.14 & 48.42 & 63.59 & 69.85 & 78.84 & 83.74 \\
\hline $\mathrm{OC}_{6} \mathrm{H}_{3} \mathrm{OCH}_{3}$ & -28.57 & 87.59 & 31.44 & 46.16 & 60.11 & 65.92 & 74.18 & 78.64 \\
\hline $\mathrm{C}_{5} \mathrm{H}_{3} \mathrm{OCH}_{3}$ & 4.85 & 78.49 & 25.49 & 38.41 & 50.55 & 55.66 & 63.09 & 67.16 \\
\hline $\mathrm{C}_{5} \mathrm{H}_{3} \mathrm{OHCH}$ & 8.68 & 80.20 & 27.67 & 41.62 & 54.44 & 59.83 & 67.81 & 72.25 \\
\hline $\mathrm{C}_{5} \mathrm{H}_{4} \mathrm{CHO}$ & 34.09 & 77.30 & 24.48 & 36.83 & 47.86 & 52.33 & 58.70 & 62.17 \\
\hline $\mathrm{C}_{5} \mathrm{H}_{5} \mathrm{CO}$ & 47.34 & 79.56 & 24.09 & 36.61 & 47.69 & 52.18 & 58.60 & 62.10 \\
\hline $\mathrm{C}_{6} \mathrm{H}_{4} \mathrm{OCHO}$ & -14.76 & 84.37 & 29.24 & 43.83 & 57.07 & 62.35 & 69.67 & 73.59 \\
\hline $\mathrm{C}_{6} \mathrm{H}_{4} \mathrm{OHCO}$ & -14.66 & 83.75 & 29.70 & 44.18 & 57.03 & 62.17 & 69.41 & 73.35 \\
\hline $\mathrm{C}_{5} \mathrm{H}_{4} \mathrm{OH} \#$ & 17.65 & 71.41 & 21.63 & 33.26 & 43.13 & 47.09 & 52.93 & 56.20 \\
\hline
\end{tabular}

Figure 1 presents the structure of guaiacol and the bond dissociation energy (BDE) calculated theoretically at the CBS-QB3 level of theory. The weakest bond is the $\mathrm{O}-\mathrm{CH}_{3}$ bond in the methoxy group with a dissociation energy as low as $58.1 \mathrm{kcal} \mathrm{mol}^{-1}$, which is significantly lower than the corresponding bond in anisole ${ }^{13}\left(63.2 \mathrm{kcal} \mathrm{mol}^{-1}\right)$. This data is consistent with the 
experimental observation of the loss of the methyl group reported in the literature as the first step in guaiacol decomposition. The second weakest bond is the $\mathrm{O}-\mathrm{H}$ bond, which BDE equals $87.1 \mathrm{kcal} \mathrm{mol}^{-1}$. This latter is very close to the value of the $\mathrm{O}-\mathrm{H}_{\text {bond in phenol }}^{51}\left(88.0 \mathrm{kcal} \mathrm{mol}^{-}\right.$ ${ }^{1}$ ). Note that the calculated $\mathrm{O}-\mathrm{H} \mathrm{BDE}$ drops down to $79.1 \mathrm{kcal} \mathrm{mol}^{-1}$ in pyrocatechol (Figure 1), the main primary product obtained during guaiacol reaction. The presence of a $-\mathrm{OCH}_{3}$ methoxy group in ortho position of the hydroxyl function in guaiacol does not affect the bond strength, whereas the substitution by a $-\mathrm{OH}$ function dramatically weakens the $\mathrm{O}-\mathrm{H}$ bond in pyrocatechol. In this latter, the produced hydroxyl phenoxy radical involves a strong intramolecular $\mathrm{H}$-bonding between the remaining $\mathrm{OH}$ group and the $\mathrm{O}$ atom, which considerably stabilized the radical. The same effect can be observed in methylcatechol (Figure 1), whereas in guaiacol, the methoxy group does not establish such a strong intramolecular bonding. This is consistent with data proposed in literature ${ }^{51}$. Finally, BDEs of the $\mathrm{C}-\mathrm{H}$ bond in the aromatic ring of guaiacol are very high, between 114.9 and $117.0 \mathrm{kcal} \mathrm{mol}^{-1}$, and make the ring unreactive in comparison to the substitute groups. BDE of $\mathrm{O}-\mathrm{H}$ bond and $\mathrm{C}-\mathrm{H}$ bonds in the methyl group in guaiacol should allow bimolecular $\mathrm{H}$-abstractions by free radicals, whereas these reactions will be neglected on the aromatic ring.
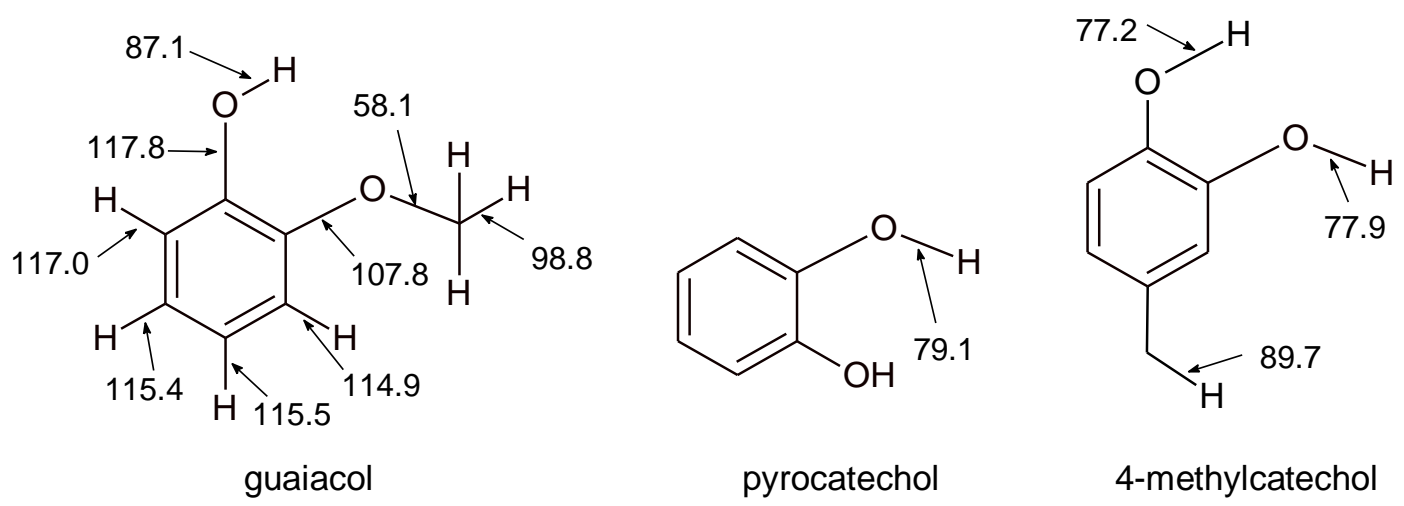

Figure 1. Bond dissociation energies at $298 \mathrm{~K}$ in guaiacol, pyrocatechol and 4-methylcatechol $\left(\mathrm{kcal} \mathrm{mol}^{-1}\right.$ ) calculated at the CBS-QB3 level of theory 
The primary mechanism for the thermal decomposition and the oxidation of guaiacol contains reactions of consumption of guaiacol and subsequent reactions of the formed radicals. The reaction types taken into account are unimolecular initiations, bimolecular initiations by $\mathrm{H}$-atom abstraction by $\mathrm{O}_{2}, \mathrm{H}$-atom abstractions by free radicals on the methyl and on the hydroxyl groups, ipso addition, and free radical isomerizations, decompositions and combinations. These primary reactions are listed in Table 2. Unimolecular initiations include the $\mathrm{O}-\mathrm{C}$ bond breaking and the loss of an $\mathrm{H}$-atom from hydroxyl and methyl groups (reactions 1-3). Rate constants were estimated from the reverse radical combinations. Reaction between methyl and 2hydroxyphenoxy radicals was suppose similar to methyl plus phenoxy radicals in anisole mechanism ${ }^{13}$. Combination of $\mathrm{H}$-atoms with radicals was estimated by analogy with reactions of alkyl radicals ${ }^{52}$. Rate constants of bimolecular initiations by $\mathrm{H}$-atom abstraction by $\mathrm{O}_{2}$ molecules are estimated from the relationships proposed by Ingham et al. for alkanes ${ }^{53}$ (reactions 4-5). Ipso additions of $\mathrm{H}$-atom, hydroxyl and methyl radicals on the carbon atom bounded to the methoxy group (reactions 6-8) have been included with the same reactivity as in anisole ${ }^{13} . \mathrm{H}$ atom abstractions from the methoxy group have been estimated as in anisole ${ }^{13}$ (reactions 9-20) while that from the hydroxyl group have been estimated by analogy with the reactions of phenol ${ }^{41,54}$ (reactions 21-33). In the case of the $\mathrm{H}$-abstraction by $\mathrm{CH}_{3} \mathrm{O}$ radical (reaction 33), for which no data was available, the activation energy was set equal to that of the reaction with acetaldehyde ${ }^{55}$. $\mathrm{OC}_{6} \mathrm{H}_{4} \mathrm{OCH}_{3}$ radical can isomerize to $\mathrm{OHC}_{6} \mathrm{H}_{4} \mathrm{OCH}_{2}$ by an internal $\mathrm{H}$-atom transfer (reaction 34), which rate constant was estimated using Benson's rules ${ }^{56,57}$. Decomposition occurs trough the elimination of $\mathrm{CO}$, with the rate constant calculated by Carstensen and Dean ${ }^{58}$ (duplicate reactions 35 and 36, which represent two parallel elementary reaction channels leading to the same product) or by bimolecular reactions with $\mathrm{H}$-atom and $\mathrm{OH}$ radicals (reactions 37-40). $\mathrm{OHC}_{6} \mathrm{H}_{4} \mathrm{OCH}_{2}$ radical reactions were written by analogy with that of the $\mathrm{C}_{6} \mathrm{H}_{5} \mathrm{OCH}_{2}$ radical derived from anisole: the decomposition by $\beta$-scission (reaction 37 ) competes with an isomerization, which consists of an internal ipso addition leading to the 
$\mathrm{HOC}_{6} \mathrm{H}_{4} \mathrm{CH}_{2} \mathrm{O}$ alkoxy radical (reaction 38). The latter decomposes further by $\beta$-scission (reactions 39-41). Rate constants theoretically calculated by Da Silva and Bozzelli for the equivalent reactions of benzaldehyde have been used ${ }^{59}$, by neglecting the effect of the hydroxyl group. The activation energy of reaction 38 was just increased by $2 \mathrm{kcal} \mathrm{mol}^{-1}$ compared to the reaction of $\mathrm{C}_{6} \mathrm{H}_{5} \mathrm{OCH}_{2}$ radical to take into account the stabilization of $\mathrm{HOC}_{6} \mathrm{H}_{4} \mathrm{CH}_{2} \mathrm{O}$ radical by an internal $\mathrm{H}$-bond between the hydroxyl group and the $\mathrm{OCH}_{2}$ moiety. Disproportionation of $\mathrm{OHC}_{6} \mathrm{H}_{4} \mathrm{OCH}_{2}$ radicals with $\mathrm{H}$-atoms, methyl and phenyl radicals, leading to the formation of hydroxybenzaldehyde, has been taken into account (reactions 42-44). The decomposition of $\mathrm{OC}_{6} \mathrm{H}_{4} \mathrm{OH}$ radical, the product of the unimolecular decomposition of guaiacol, has been theoretically studied by Altarawneh et al. ${ }^{60}$. The two main decomposition channels occur by a $\mathrm{H}$ atom elimination yielding o-benzoquinone $\mathrm{OC}_{6} \mathrm{H}_{4} \mathrm{O}$ (reaction 46) and a $\mathrm{CO}$ elimination leading to a $\mathrm{C}_{5} \mathrm{H}_{4} \mathrm{OH}$ radical (reaction 45 ). Theoretical rate constant calculated theoretically by these authors at the BB1K/GTLarge//BB1K/6-311+G(d,p) level of theory was used for reaction 45 but this rate leads in the case of reaction 46 to too high stability of the $\mathrm{OC} 6 \mathrm{H} 4 \mathrm{OH}$ radical and to a dramatic underprediction of $\mathrm{CO}$ in both pyrolysis and oxidation, which is incompatible with experimental observations. Then, the rate constant of reaction 45 was estimated by analogy similar to that of the reaction of phenoxy radical ${ }^{61}$ used in the model of anisole ${ }^{13}$. The low reactivity of $\mathrm{OC}_{6} \mathrm{H}_{4} \mathrm{OH}$ radicals favors however the formation of pyrocatechol by combination with $\mathrm{H}$-atoms or disproportionation with $\mathrm{HO}_{2}$ radicals in oxidation conditions (reactions 47 and 51). Rate constants were estimated from reactions of hydrocarbon radicals ${ }^{52,56}$. Reactions with methyl radicals were written by analogy with the reactions of phenoxy radical proposed by Pecullan et al. ${ }^{62}$. Products are methylcatechols or related radicals (reaction 48-50). Note that 3and 4-methylcatechols are not distinguished in the model but gathered into a sole species. Rate constants are that from Pecullan et al. ${ }^{62}$, except the rate of reaction 47 , which was decreased by a factor of 10 because of the larger stability of 2-hydroxyphenoxy radical compared with phenoxy radical. Other bimolecular reactions of $\mathrm{OC}_{6} \mathrm{H}_{4} \mathrm{OH}$ radicals with $\mathrm{O}$-atom, $\mathrm{O}_{2}$ and $\mathrm{HO}_{2}$ (reactions 
52-54) can occur by addition or $\mathrm{H}$-atom abstraction yielding o-benzoquinone $\mathrm{OC}_{6} \mathrm{H}_{4} \mathrm{O}$. Their rate constants were estimated by analogy with reactions of phenoxy radical and of reaction of small oxygenates ${ }^{13}$.

A sub-mechanism was developed for the consumption of primary products, which were not involved in the anisole mechanism used as a starting base. These reactions are not included in Table 2 but in the mechanism available in Supplemental Material. Pyrocatechol $0-\mathrm{HOC}_{6} \mathrm{H}_{4} \mathrm{OH}$ can decompose into small molecules by unimolecular reactions, as investigated by Altarawneh et al., ${ }^{63}$ but rather react by $\mathrm{H}$-atom abstractions yielding again 2-hydroxyphenoxy radicals and by the ipso addition of methyl radicals producing methylcatechol. This latter reacts by $\mathrm{H}$-atom abstraction by $\mathrm{O}_{2}$ or radicals from both hydroxy groups, which produce $\mathrm{OC}_{6} \mathrm{H}_{3} \mathrm{OHCH}_{3}$ and $\mathrm{HOC}_{6} \mathrm{H}_{3} \mathrm{OCH}_{3}$ radicals. These radicals can decompose by $\mathrm{CO}$ elimination or react in bimolecular reactions with $\mathrm{H}$ or $\mathrm{O}$-atoms, by analogy with phenoxy and hydroxyphenoxy radicals. 0 Benzoquinone produced from $\mathrm{OC}_{6} \mathrm{H}_{4} \mathrm{OH}$ radicals decomposes easily through a concerted reaction to $\mathrm{CO}$ and cyclopentadienone.$^{64}$ This latter can react by addition of radicals on double bonds or in further molecular decompositions ${ }^{65}$. Eventually, reaction of 2-hydroxybenzaldehyde $\mathrm{C}_{6} \mathrm{H}_{4} \mathrm{OHCHO}$ was written by analogy with that of phenol and benzaldehyde. Note that few reactions of methanol sub-mechanism were revisited in comparison with the model of anisole ${ }^{13}$. The rate constant of the $\mathrm{H}$-atom abstraction from methanol by $\mathrm{H}$-atom yielding $\mathrm{H}_{2}$ and $\mathrm{CH}_{2} \mathrm{OH}$ radical was up-dated with a recent theoretical value by Meana-Peñada et al. ${ }^{66}$. The very sensitive decomposition of $\mathrm{CH}_{3} \mathrm{O}$ radical to formaldehyde and $\mathrm{H}$-atom uses the pressure dependent rate constant determined by Hippler et al. ${ }^{67}$, with low pressure limit and Troe fall-off coefficients determined in helium, which is the bath gas used in the present study. 
Table 2. Primary Mechanism for Guaiacol Pyrolysis and Oxidation. Rate Constants are in the Form $A T^{n} \exp \left(-E_{a} / R T\right)$ in $\mathrm{cm}, \mathrm{mol}, \mathrm{s}$, and cal units

\begin{tabular}{|c|c|c|c|c|}
\hline & Reaction & A & $\mathrm{n}$ & $\mathrm{E}_{\mathrm{a}}$ \\
\hline & Initiations & & & \\
\hline 1. & $\mathrm{OC}_{6} \mathrm{H}_{4} \mathrm{OH}+\mathrm{CH}_{3}=$ guaiacol & $5.00 \mathrm{E}+12$ & 0 & 0 \\
\hline 2. & $\mathrm{OHC}_{6} \mathrm{H}_{4} \mathrm{OCH}_{2}+\mathrm{H}=$ guaiacol & $1.00 \mathrm{E}+14$ & 0 & 0 \\
\hline 3. & $\begin{array}{l}\mathrm{OC}_{6} \mathrm{H}_{4} \mathrm{OCH}_{3}+\mathrm{H}=\text { guaiacol } \\
\text { Bimolecular initiations }\end{array}$ & $1.00 \mathrm{E}+14$ & 0 & 0 \\
\hline 4. & Guaiacol $+\mathrm{O}_{2}=\mathrm{OHC}_{6} \mathrm{H}_{4} \mathrm{OCH}_{2}+\mathrm{HO}_{2}$ & $2.10 \mathrm{E}+13$ & 0 & 50169 \\
\hline 5. & $\begin{array}{l}\text { Guaiacol }+\mathrm{O}_{2}=\mathrm{OC}_{6} \mathrm{H}_{4} \mathrm{OCH}_{3}+\mathrm{HO}_{2} \\
\text { Ipso-additions on guaiacol }\end{array}$ & $7.00 \mathrm{E}+12$ & 0 & 38410 \\
\hline 6. & Guaiacol $+\mathrm{H}=\mathrm{C}_{6} \mathrm{H}_{5} \mathrm{OH}+\mathrm{CH}_{3} \mathrm{O}$ & $2.23 \mathrm{E}+13$ & 0 & 10930 \\
\hline 7. & Guaiacol $+\mathrm{CH}_{3}=\mathrm{HOC}_{6} \mathrm{H}_{4} \mathrm{CH}_{3}+\mathrm{CH}_{3} \mathrm{O}$ & $9.64 \mathrm{E}+10$ & 0 & 8000 \\
\hline 8. & $\begin{array}{l}\text { Guaiacol }+\mathrm{OH}=\text { pyrocatechol }+\mathrm{CH}_{3} \mathrm{O} \\
\mathrm{H} \text {-atom abstraction from the } \mathrm{CH}_{3} \text { group }\end{array}$ & $7.80 \mathrm{E}+02$ & 2.88 & 3220 \\
\hline 9. & Guaiacol $+\mathrm{H}=\mathrm{OHC}_{6} \mathrm{H}_{4} \mathrm{OCH}_{2}+\mathrm{H}_{2}$ & $3.60 \mathrm{E}+08$ & 1.5 & 6905 \\
\hline 10. & Guaiacol $+\mathrm{CH}_{3}=\mathrm{OHC}_{6} \mathrm{H}_{4} \mathrm{OCH}_{2}+\mathrm{CH}_{4}$ & $5.01 \mathrm{E}+11$ & 0 & 10500 \\
\hline 11. & Guaiacol $+\mathrm{OH}=\mathrm{OHC}_{6} \mathrm{H}_{4} \mathrm{OCH}_{2}+\mathrm{H}_{2} \mathrm{O}$ & $3.60 E+06$ & 2 & -855 \\
\hline 12. & Guaiacol $+\mathrm{HO}_{2}=\mathrm{OHC}_{6} \mathrm{H}_{4} \mathrm{OCH}_{2}+\mathrm{H}_{2} \mathrm{O}_{2}$ & $4.20 \mathrm{E}+03$ & 2.69 & 16592 \\
\hline 13. & Guaiacol $+\mathrm{C}_{2} \mathrm{H}_{5}=\mathrm{OHC}_{6} \mathrm{H}_{4} \mathrm{OCH}_{2}+\mathrm{C}_{2} \mathrm{H}_{6}$ & $3.00 \mathrm{E}+11$ & 0 & 9200 \\
\hline 14. & Guaiacol $+\mathrm{C}_{5} \mathrm{H}_{5}=\mathrm{OHC}_{6} \mathrm{H}_{4} \mathrm{OCH}_{2}+\mathrm{C}_{5} \mathrm{H}_{6}$ & $5.40 \mathrm{E}+00$ & 3.3 & 17200 \\
\hline 15. & Guaiacol $+\mathrm{C}_{6} \mathrm{H}_{5}=\mathrm{OHC}_{6} \mathrm{H}_{4} \mathrm{OCH}_{2}+\mathrm{C}_{6} \mathrm{H}_{6}$ & $3.00 \mathrm{E}+11$ & 0 & 3851 \\
\hline 16. & $\mathrm{OHC}_{6} \mathrm{H}_{4} \mathrm{OCH}_{2}+$ pyrocatechol = guaiacol $+\mathrm{OC}_{6} \mathrm{H}_{4} \mathrm{OH}$ & $1.80 \mathrm{E}+11$ & 0 & 7700 \\
\hline 17. & Guaiacol $+\mathrm{O}=\mathrm{OHC}_{6} \mathrm{H}_{4} \mathrm{OCH}_{2}+\mathrm{OH}$ & $3.00 \mathrm{E}+13$ & 0 & 3280 \\
\hline 18. & Guaiacol $+\mathrm{CH}_{3} \mathrm{O}=\mathrm{CH}_{3} \mathrm{OH}+\mathrm{OHC}_{6} \mathrm{H}_{4} \mathrm{OCH}_{2}$ & $2.16 \mathrm{E}+11$ & 0 & 4500 \\
\hline 19. & Guaiacol $+\mathrm{CH}_{3} \mathrm{OO}=\mathrm{OHC}_{6} \mathrm{H}_{4} \mathrm{OCH}_{2}+\mathrm{CH}_{3} \mathrm{OOH}$ & $4.50 \mathrm{E}+12$ & 0 & 17500 \\
\hline 20. & $\begin{array}{l}\text { Guaiacol }+\mathrm{C}_{6} \mathrm{H}_{4} \mathrm{OH}=\mathrm{OHC}_{6} \mathrm{H}_{4} \mathrm{OCH}_{2}+\mathrm{C}_{6} \mathrm{H}_{5} \mathrm{OH} \\
\mathrm{H} \text {-atom abstraction from the } \mathrm{OH} \text { group }\end{array}$ & $3.00 \mathrm{E}+11$ & 0 & 3851 \\
\hline 21. & Guaiacol $+\mathrm{H}=\mathrm{OC}_{6} \mathrm{H}_{4} \mathrm{OCH}_{3}+\mathrm{H}_{2}$ & $1.20 \mathrm{E}+14$ & 0 & 12400 \\
\hline 22. & Guaiacol $+\mathrm{CH}_{3}=\mathrm{OC}_{6} \mathrm{H}_{4} \mathrm{OCH}_{3}+\mathrm{CH}_{4}$ & $1.80 \mathrm{E}+11$ & 0 & 7700 \\
\hline 23. & Guaiacol $+\mathrm{OH}=\mathrm{OC}_{6} \mathrm{H}_{4} \mathrm{OCH}_{3}+\mathrm{H}_{2} \mathrm{O}$ & $1.40 \mathrm{E}+08$ & 1.4 & -960 \\
\hline 24. & Guaiacol $+\mathrm{HO}_{2}=\mathrm{OC}_{6} \mathrm{H}_{4} \mathrm{OCH}_{3}+\mathrm{H}_{2} \mathrm{O}_{2}$ & $1.00 \mathrm{E}+12$ & 0 & 10000 \\
\hline
\end{tabular}




\begin{tabular}{|c|c|c|c|c|}
\hline 25. & Guaiacol $+\mathrm{C}_{5} \mathrm{H}_{5}=\mathrm{OC}_{6} \mathrm{H}_{4} \mathrm{OCH}_{3}+\mathrm{C}_{5} \mathrm{H}_{6}$ & $2.67 E+14$ & 0 & 25200 \\
\hline 26. & Guaiacol $+\mathrm{C}_{6} \mathrm{H}_{5}=\mathrm{OC}_{6} \mathrm{H}_{4} \mathrm{OCH}_{3}+\mathrm{C}_{6} \mathrm{H}_{6}$ & $4.90 \mathrm{E}+12$ & 0 & 4400 \\
\hline 27. & Guaiacol $+\mathrm{O}=\mathrm{OC}_{6} \mathrm{H}_{4} \mathrm{OCH}_{3}+\mathrm{OH}$ & $1.30 \mathrm{E}+13$ & 0 & 2900 \\
\hline 28. & Guaiacol $+\mathrm{aC}_{3} \mathrm{H}_{5}=\mathrm{OC}_{6} \mathrm{H}_{4} \mathrm{OCH}_{3}+\mathrm{C}_{3} \mathrm{H}_{6}$ & 2.67E+14 & 0 & 25200 \\
\hline 29. & Guaiacol $+\mathrm{iC}_{4} \mathrm{H}_{5}=\mathrm{OC}_{6} \mathrm{H}_{4} \mathrm{OCH}_{3}+1,3-\mathrm{C}_{4} \mathrm{H}_{6}$ & $2.67 E+14$ & 0 & 25200 \\
\hline 30. & Guaiacol $+\mathrm{OC}_{6} \mathrm{H}_{4} \mathrm{OH}=\mathrm{OC}_{6} \mathrm{H}_{4} \mathrm{OCH}_{3}+$ pyrocatechol & $1.05 E+11$ & 0 & 11500 \\
\hline 31. & Guaiacol $+\mathrm{CH}_{3} \mathrm{O}=\mathrm{CH}_{3} \mathrm{OH}+\mathrm{OC}_{6} \mathrm{H}_{4} \mathrm{OCH}_{3}$ & $1.00 \mathrm{E}+12$ & 0 & 1240 \\
\hline 32. & Guaiacol $+\mathrm{CH}_{3} \mathrm{OO}=\mathrm{OC}_{6} \mathrm{H}_{4} \mathrm{OCH}_{3}+\mathrm{CH}_{3} \mathrm{OOH}$ & $1.00 \mathrm{E}+12$ & 0 & 10000 \\
\hline 33. & $\begin{array}{l}\mathrm{C}_{6} \mathrm{H}_{4} \mathrm{OH}+\text { guaiacol }=\mathrm{C}_{6} \mathrm{H}_{5} \mathrm{OH}+\mathrm{OC}_{6} \mathrm{H}_{4} \mathrm{OCH}_{3} \\
\text { Radical isomerization and decomposition }\end{array}$ & $4.90 \mathrm{E}+12$ & 0 & 4400 \\
\hline 34. & $\mathrm{OC}_{6} \mathrm{H}_{4} \mathrm{OCH}_{3}=\mathrm{OHC}_{6} \mathrm{H}_{4} \mathrm{OCH}_{2}$ & $5.02 E+09$ & 1 & 25000 \\
\hline 35. & $\mathrm{OC}_{6} \mathrm{H}_{4} \mathrm{OCH}_{3} \rightarrow \mathrm{CO}+\mathrm{CH}_{3}+\mathrm{C}_{5} \mathrm{H}_{4} \mathrm{O}$ & $3.30 \mathrm{E}+14$ & 0 & 58000 \\
\hline 36. & $\mathrm{OC}_{6} \mathrm{H}_{4} \mathrm{OCH}_{3} \rightarrow \mathrm{CO}+\mathrm{CH}_{3}+\mathrm{C}_{5} \mathrm{H}_{4} \mathrm{O}$ & $2.10 \mathrm{E}+14$ & 0 & 59600 \\
\hline 37. & $\mathrm{OHC}_{6} \mathrm{H}_{4} \mathrm{OCH}_{2}=\mathrm{HCHO}+\mathrm{C}_{6} \mathrm{H}_{4} \mathrm{OH}$ & $2.61 \mathrm{E}+14$ & 0.05 & 39280 \\
\hline 38. & $\mathrm{OHC}_{6} \mathrm{H}_{4} \mathrm{OCH}_{2}=\mathrm{HOC}_{6} \mathrm{H}_{4} \mathrm{CH}_{2} \mathrm{O}$ & $8.78 \mathrm{E}+10$ & 0.44 & 21030 \\
\hline 39. & $\mathrm{HOC}_{6} \mathrm{H}_{4} \mathrm{CH}_{2} \mathrm{O}=\mathrm{C}_{6} \mathrm{H}_{4} \mathrm{OHCHO}+\mathrm{H}$ & $5.26 \mathrm{E}+28$ & -5.08 & 22300 \\
\hline 40. & $\mathrm{HOC}_{6} \mathrm{H}_{4} \mathrm{CH}_{2} \mathrm{O}=\mathrm{C}_{6} \mathrm{H}_{5} \mathrm{OH}+\mathrm{CHO}$ & 2.37E+32 & -6.09 & 28800 \\
\hline 41. & $\mathrm{HOC}_{6} \mathrm{H}_{4} \mathrm{CH}_{2} \mathrm{O}=\mathrm{HCHO}+\mathrm{C}_{6} \mathrm{H}_{4} \mathrm{OH}$ & $7.21 E+33$ & -6.21 & 36900 \\
\hline 42. & $\mathrm{HOC}_{6} \mathrm{H}_{4} \mathrm{CH}_{2} \mathrm{O}+\mathrm{H}=\mathrm{C}_{6} \mathrm{H}_{4} \mathrm{OHCHO}+\mathrm{H}_{2}$ & $1.00 \mathrm{E}+13$ & 0 & 0 \\
\hline 43. & $\mathrm{HOC}_{6} \mathrm{H}_{4} \mathrm{CH}_{2} \mathrm{O}+\mathrm{CH}_{3}=\mathrm{C}_{6} \mathrm{H}_{4} \mathrm{OHCHO}+\mathrm{CH}_{4}$ & $1.00 \mathrm{E}+12$ & 0 & 0 \\
\hline 44. & $\begin{array}{l}\mathrm{HOC}_{6} \mathrm{H}_{4} \mathrm{CH}_{2} \mathrm{O}+\mathrm{C}_{6} \mathrm{H}_{5}=\mathrm{C}_{6} \mathrm{H}_{4} \mathrm{OHCHO}+\mathrm{C}_{6} \mathrm{H}_{6} \\
\text { Reactions of } \mathrm{OC}_{6} \mathrm{H}_{4} \mathrm{OH} \text { radicals }\end{array}$ & $1.00 \mathrm{E}+12$ & 0 & 0 \\
\hline 45. & $\mathrm{OC}_{6} \mathrm{H}_{4} \mathrm{OH}=\mathrm{H}+\mathrm{OC}_{6} \mathrm{H}_{4} \mathrm{O}$ & $7.63 E+14$ & 0 & 71930 \\
\hline 46. & $\mathrm{OC}_{6} \mathrm{H}_{4} \mathrm{OH}=\mathrm{CO}+\mathrm{C}_{5} \mathrm{H}_{4} \mathrm{OH}$ & $6.17 E+78$ & -18.79 & 90504 \\
\hline 47. & $\mathrm{OC}_{6} \mathrm{H}_{4} \mathrm{OH}+\mathrm{H}=$ pyrocatechol & $1.00 \mathrm{E}+14$ & 0 & 0 \\
\hline 48. & $\mathrm{OC}_{6} \mathrm{H}_{4} \mathrm{OH}+\mathrm{CH}_{3}=$ methylcatechol & $2.31 \mathrm{E}+72$ & -17.37 & 38780 \\
\hline 49. & $\mathrm{OC}_{6} \mathrm{H}_{4} \mathrm{OH}+\mathrm{CH}_{3}=\mathrm{OC}_{6} \mathrm{H}_{3} \mathrm{OHCH}_{3}+\mathrm{H}$ & $3.33 E+39$ & -7.78 & 31670 \\
\hline 50. & $\mathrm{OC}_{6} \mathrm{H}_{4} \mathrm{OH}+\mathrm{CH}_{3}=\mathrm{HOC}_{6} \mathrm{H}_{3} \mathrm{OCH}_{3}+\mathrm{H}$ & $3.33 E+39$ & -7.78 & 31670 \\
\hline 51. & pyrocatechol $+\mathrm{O}_{2}=\mathrm{OC}_{6} \mathrm{H}_{4} \mathrm{OH}+\mathrm{HO}_{2}$ & $1.40 \mathrm{E}+12$ & 0 & 30441 \\
\hline 52. & $\mathrm{OC}_{6} \mathrm{H}_{4} \mathrm{OH}+\mathrm{O}=\mathrm{C}_{5} \mathrm{H}_{4} \mathrm{OH}+\mathrm{CO}_{2}$ & $1.0 e+13$ & 0 & 0 \\
\hline 53. & $\mathrm{OC}_{6} \mathrm{H}_{4} \mathrm{OH}+\mathrm{O}_{2}=\mathrm{OC}_{6} \mathrm{H}_{4} \mathrm{O}+\mathrm{HO}_{2}$ & $1.0 \mathrm{E}+13$ & 0 & 19051 \\
\hline 54. & $\mathrm{OC}_{6} \mathrm{H}_{4} \mathrm{OH}+\mathrm{HO}_{2}=\mathrm{OC}_{6} \mathrm{H}_{4} \mathrm{O}+\mathrm{H}_{2} \mathrm{O}_{2}$ & $3.0 \mathrm{E}+11$ & 0 & 0 \\
\hline
\end{tabular}

\section{Results}

\section{Thermal decomposition of guaiacol}

The pyrolysis of guaiacol was carried out as a function of the temperature in the conditions described above, i.e. $0.5 \%$ of reactant in the helium flow, a residence time of $2 \mathrm{~s}$ and a pressure of 800 Torr $(106.7 \mathrm{kPa})$. The conversion of the reactant was quantified as well as the mole fraction of 24 detected species, including 14 light compounds, i.e. containing up to 5 carbon 
atoms, and 10 heavy compounds involving at least 6 carbon atoms. Light products are hydrogen, carbon monoxide, alkanes (methane, ethane, propane), alkenes (ethylene, propene, allene (propadiene), 1,3-butadiene), alkynes (acetylene, propyne, vinylacetylene (1-buten-3yne)) as well as cyclopentadiene. The heavy products involve an aromatic ring: anisole, phenol, cresols (2-and 4-methylphenols) and 2-ethylphenol, 2-hydroxy benzaldehyde, 2,3dihydrobenzofuran, pyrocatechol and 3- and 4-methylcatechols.

The evolution of the mole fraction of the reactant is displayed in figure 2 . Figure 3 to 5 presents mole fraction profiles of $\mathrm{C}_{0}-\mathrm{C}_{2}$ products, $\mathrm{C}_{3}-\mathrm{C}_{5}$ products, and aromatic heavy products, respectively. In all the figures, dots represent experiments and lines simulations. The reaction begins around $700 \mathrm{~K}$. A conversion rate of $50 \%$ is reached around $780 \mathrm{~K}$ and guaiacol is totally consumed above $875 \mathrm{~K}$.

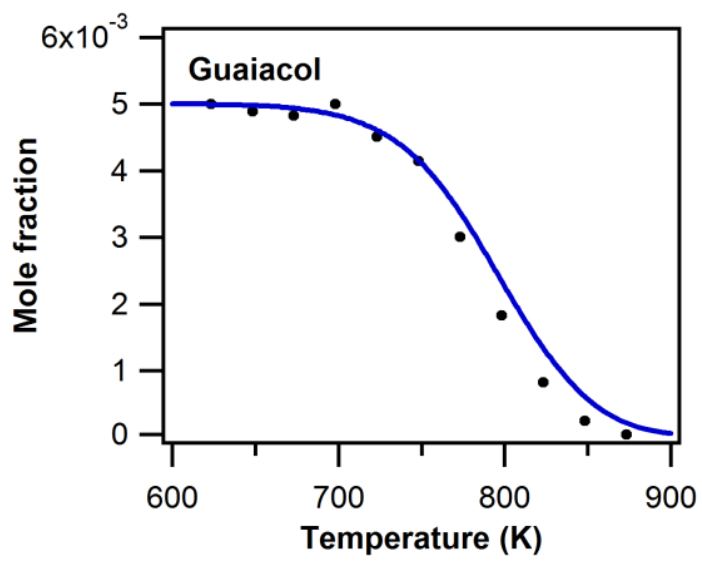

Figure 2. Evolution of the mole fraction of guaiacol in pyrolysis as a function of the temperature. Points are experimental data and line model predictions

On the studied temperature range, the profiles of light products (Figure 3) increase monotonically with temperature, except for methane. Methane is the first detected product at a temperature as low as $648 \mathrm{~K}$ and its mole fraction reaches a maximum of $1000 \mathrm{ppm}$ at $873 \mathrm{~K}$. 
This early formation is consistent with the break of the weakest bond in the molecule (figure 1) as proposed in the literature, leading to the formation of $\mathrm{CH}_{3}$ and $\mathrm{OC}_{6} \mathrm{H}_{4} \mathrm{OH}$ radicals. Methyl radicals react thereafter by $\mathrm{H}$-atom abstraction to lead to methane. Ethane, the most abundant among the $\mathrm{C}_{2}$ compounds, is produced simultaneously by the combination of methyl radicals. 5 ppm of ethane are quantified at $698 \mathrm{~K}$, and its mole fraction reaches $600 \mathrm{ppm}$ at $900 \mathrm{~K}$. The increase of temperature up to $748 \mathrm{~K}$ permits the observation of ethylene and carbon monoxide. By analogy with anisole ${ }^{13}$, the main source of carbon monoxide can be assume to be the loss of $\mathrm{CO}$ from $\mathrm{OC}_{6} \mathrm{H}_{4} \mathrm{OH}$ radical or the decomposition of the 2-hydroxybenzaldehyde, which is formed at low temperature (Figure 5). Heavier $\mathrm{C}_{2}-\mathrm{C}_{5}$ products are quantified for higher temperatures (Figure 4), from $798 \mathrm{~K}$, but they remain however very minor with mole fractions below $50 \mathrm{ppm}$ (propene, propyne, 1,3-butadiene) or even less (allene, propane, 1-butene) in the temperature range studied. The only decomposition products formed in significant quantities are vinylacetylene and cyclopentadiene, which reach 100 and 150 ppm, respectively.

The main reaction products are aromatics (displayed in Figure 5 and S1 in Supplemental information). At $773 \mathrm{~K}$, the experimental conversion of guaiacol reaches $40 \%$ and selectivities of pyrocatechol $0-\mathrm{HOC}_{6} \mathrm{H}_{4} \mathrm{OH}$ and 2-hydroxybenzaldehyde $\mathrm{C}_{6} \mathrm{H}_{4} \mathrm{OHCHO}$ among carbonated products are $40 \%$ and $17 \%$, respectively, whereas selectivities of carbon monoxide, methane and ethane are only $12 \%, 11 \%$, and $5 \%$, respectively. Methylcatechols account for about $5 \%$, phenol and 2-methylphenol for about $2 \%$ each. The increase of the reaction temperature enhances the selectivity of small decomposition products, especially $\mathrm{CO}$ and light alkanes, but pyrocatechol and 2-hydroxybenzaldehyde account still for 33\% and $5 \%$ respectively at $873 \mathrm{~K}$ while guaiacol conversion reaches $99 \%$. The majority of the profiles of aromatics exhibits a bell shape with maxima around $800-850 \mathrm{~K}$. At the lowest temperatures studied, the main products are pyrocatechol, 2-hydroxybenzaldehyde and 2-methylphenol (o-cresol o- $\mathrm{HOC}_{6} \mathrm{H}_{4} \mathrm{CH}_{3}$ ), which are produced from the primary decomposition of guaiacol. Pyrocatechol can be produced by the combination of a $\mathrm{OC}_{6} \mathrm{H}_{4} \mathrm{OH}$ radical with a $\mathrm{H}$-atom. Its mole fraction peaks at $3600 \mathrm{ppm}$ around 
848K. 2-Hydroxybenzaldehyde (maximum mole fraction of $600 \mathrm{ppm}$ at $823 \mathrm{~K}$ ) can be formed as benzaldehyde in the case of anisole ${ }^{13}$ : first, a $\mathrm{OHC}_{6} \mathrm{H}_{4} \mathrm{OCH}_{2}$ radical is produced by a $\mathrm{H}$-atom abstraction on the methoxy group of guaiacol. The radical isomerizes very rapidly to $\mathrm{HOC}_{6} \mathrm{H}_{4} \mathrm{CH}_{2} \mathrm{O}$ radical, which decomposes to 2-hydroxybenzaldehyde by the loss of a hydrogen atom by $\beta$-scission. The last product quantified at $648 \mathrm{~K}$ is 2-methylphenol with a maximum mole fraction around $35 \mathrm{ppm}$ at $798 \mathrm{~K}$. This product is probably formed by the ipso-addition of methyl radicals to guaiacol. When temperature increases above $700 \mathrm{~K}$, phenol and methylcatechols are also present among the main products. The first peaks at $80 \mathrm{ppm}$ at $823 \mathrm{~K}$. 3-Methylcathecol and 4-methylcathecols are produced together in similar amounts from $723 \mathrm{~K}$. The sum of methylcatechols is presented in figure 5 since the two detected isomers are merged in the model, but individual profiles can be seen in figure $\mathrm{S} 2$ in supplemental material. At the maximum at $823 \mathrm{~K}$, the total mole fraction of the 3- and 4-methylcatechols is $410 \mathrm{ppm}$. These products are probably formed by the same type of reaction as cresols in the case of anisole ${ }^{62,13}$, i.e. a direct reaction between methyl and $\mathrm{OC}_{6} \mathrm{H}_{4} \mathrm{OH}$ radicals. Note that formation pathways and reactivity look almost the same for 3- and 4-methylcatechols: the two products are formed simultaneously in similar amounts and have maxima at the same temperature. Minor quantified aromatics are anisole with a maximum molar fraction of $12 \mathrm{ppm}$ at $823 \mathrm{~K}$, and 2-ethylphenol and 2,3dihydrobenzofuran, which are presented in figure S2.
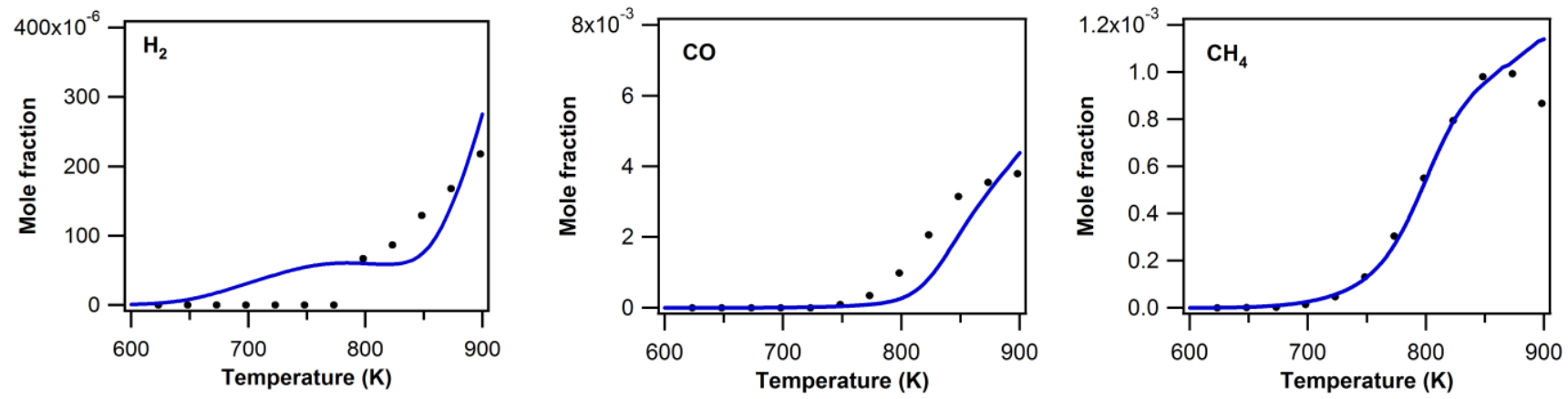

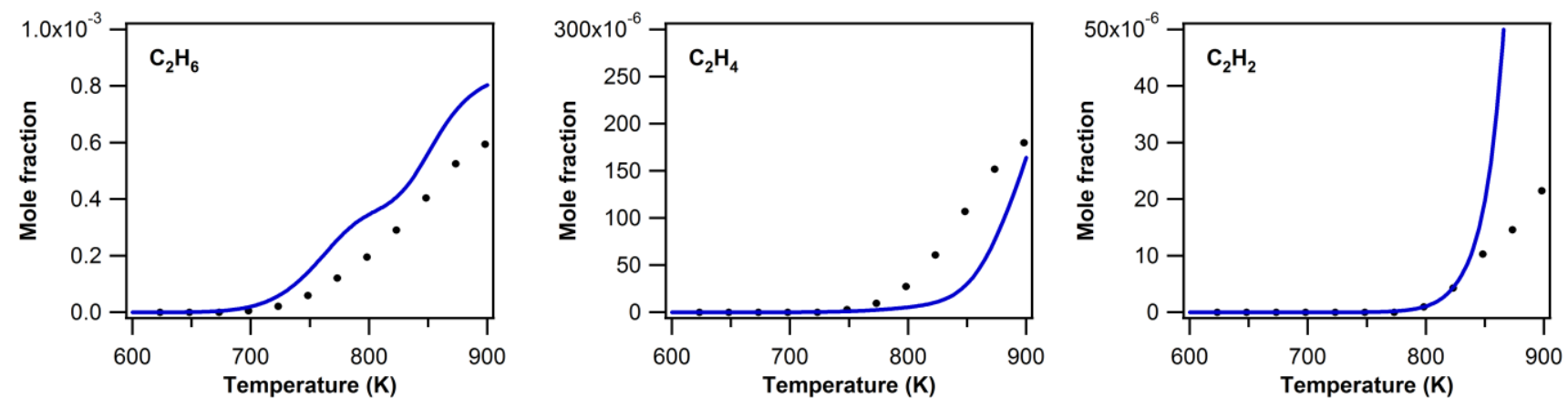

Figure 3. Evolution of mole fractions of light $\mathrm{C}_{0}-\mathrm{C}_{2}$ products during the pyrolysis of guaiacol.
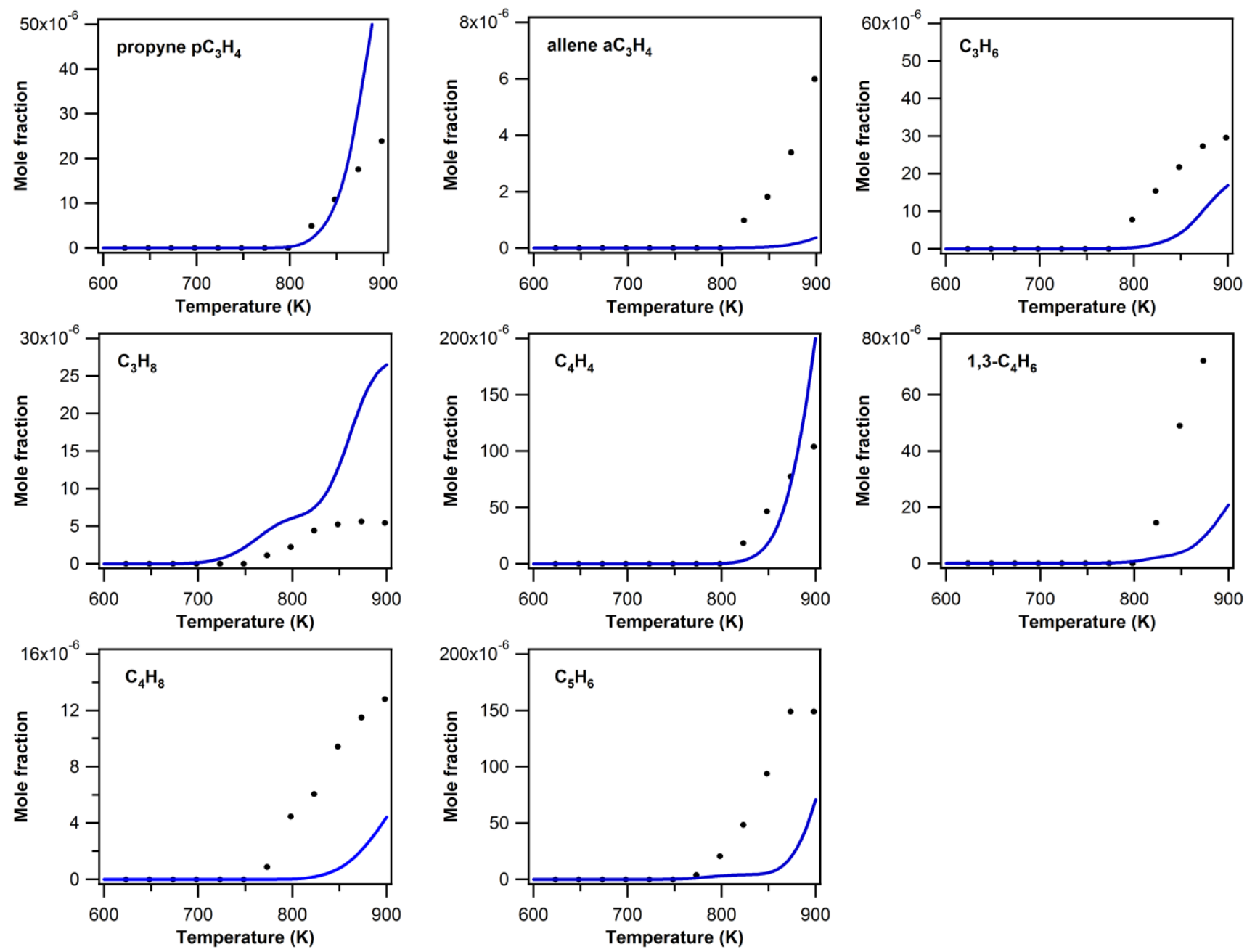

Figure 4. Evolution of mole fractions of light $\mathrm{C}_{3}-\mathrm{C}_{5}$ products during the pyrolysis of guaiacol. 

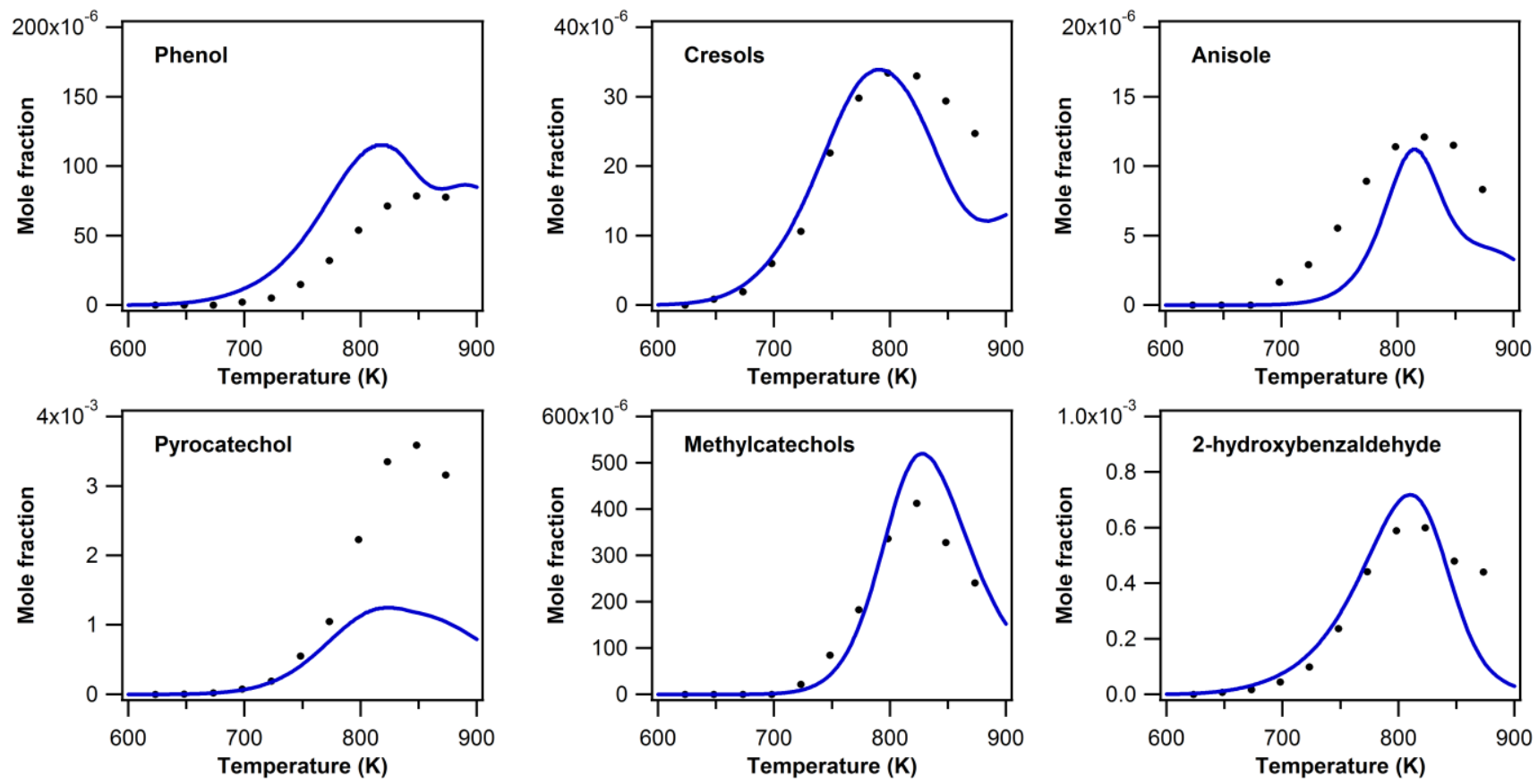

Figure 5. Evolution of mole fractions of aromatic products during the pyrolysis of guaiacol.

\section{Oxidation of Guaiacol}

The oxidation of guaiacol was carried out at stoichiometry $(\varphi=1)$ over the temperature range $573 \mathrm{~K}-923 \mathrm{~K}$. The concentration of guaiacol was $0.5 \%$ in helium, pressure was set to 800 Torr and residence time to $2 \mathrm{~s}$. Figure 6 presents the conversion of the reactants as a function of the temperature. In oxidation in the studied conditions, guaiacol begins to decompose around $690 \mathrm{~K}$. A conversion rate of $50 \%$ is reached at about $780 \mathrm{~K}$ and a complete decomposition above $873 \mathrm{~K}$. For comparison, the conversion of guaiacol in pyrolysis was also plotted in figure 6. It appears that the addition of oxygen shifts the reactivity by $25 \mathrm{~K}$ toward lower temperatures. Oxygen consumption starts at $723 \mathrm{~K}$ and increases with temperature. At $900 \mathrm{~K}$, one third of the initial oxygen amount is consumed. Forty two reactions products were detected. 
Figures 7 to 9 display the mole fraction of the main products. Mole fractions of minor products are available in Figures S3 and S4 in Supplemental Material. Except propane and 4methylphenol, all products detected in pyrolysis were also observed in oxidation. Other products detected in oxidation were carbon dioxide, hydrocarbons (1,3-and 1,4-pentadiene, benzene, and naphthalene), and oxygenates: methanol, aldehydes (acetaldehyde, propanal, 2-butenal, metacroleine), unsaturated cyclic ethers (furan, 2-methylfuran), one cyclic ester (alpha-pyrone $\mathrm{C}_{5} \mathrm{H}_{4} \mathrm{O}_{2}$ ), and aromatics (2-ethoxyphenol, resorcinol (1,3-benzenediol), benzaldehyde, 2methylbenzofuran, $\mathrm{C}_{9} \mathrm{H}_{8} \mathrm{O}$, 1-indenol, 1 naphtol, and 2,2-biphenyldiol). In addition to carbon oxides, which are the main products in oxidation, the highest selectivities among the reaction products at $773 \mathrm{~K}$ remain that of 2-hydroxybenzaldehyde and pyrocatechol, which were the main products in pyrolysis, plus that of methanol, which accounts for $8 \%$.

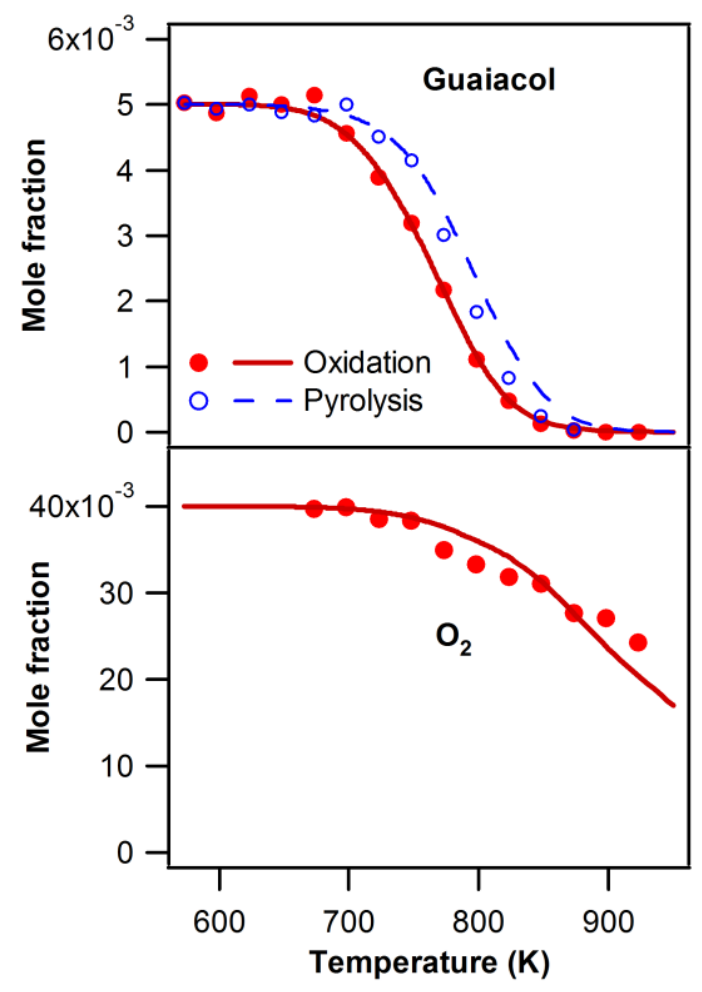

Figure 6. Evolution of the mole fractions of reactants during the oxidation of guaiacol. 
Light products involving up to two carbon atoms are gathered in figure 7. Carbon oxides are produced from the lowest temperature around $700 \mathrm{~K}$. The formation of carbon dioxide at such a low temperature is unusual and may be due to a specific low temperature reaction channel, e.g. the oxidation of 2-hydroxybenzaldehyde. Compared to pyrolysis, acetylene and ethylene yields are higher whereas the mole fraction of ethane drops. Among light oxygenates, methanol fraction reaches a maximum at $773 \mathrm{~K}$ while acetaldehyde is produced at higher temperature. $\mathrm{C}_{3^{-}}$ $\mathrm{C}_{5}$ hydrocarbons and oxygenates are presented in figures 8 and $\mathrm{S} 3$, respectively. Their mole fractions remain low whatever the temperature, below 50 ppm for most of them, except propene which reach a mole fraction of $80 \mathrm{ppm}$ at $900 \mathrm{~K}$. Among oxygenates, the main product is furan (maximum of $230 \mathrm{ppm}$ at $873 \mathrm{~K}$ ), which production starts around $700 \mathrm{~K}$. Note that its formation, as that of the lactone alpha-pyrone, cannot derive from unimolecular decompositions of guaiacol or main primary reaction products, such as pyrocatechol or 2-hydroxybenzaldehyde, since they were not observed in pyrolysis.

Aromatics are the major reaction products, as in pyrolysis, and are presented in figures 9 and S4. All products except benzene and naphthalene have bell-shaped profiles. Main primary products remain 2-hydroxybenzaldehyde and pyrocatechol, which reach 900 ppm and 700 ppm at $798 \mathrm{~K}$ and $823 \mathrm{~K}$, respectively. Cresols and methylcatechols are also formed during oxidation, but in lower amounts than in pyrolysis, whereas anisole fraction remains almost unchanged. (Figure 9). Aromatic hydrocarbons were not detected in pyrolysis, even at high conversion, while benzene and naphthalene are produced in oxidation. They appear from $748 \mathrm{~K}$ and $773 \mathrm{~K}$ and their fraction increase linearly with temperature, even if the fraction of the latter remains low (1.9 ppm at $923 \mathrm{~K}$ ). Benzaldehyde (figure 9) and resorcinol (1,3-benzenediol, figure S4), are produced in oxidation up to $40 \mathrm{ppm}$. Among the minor phenolic products, 2-ethoxyphenol and 2,2-bisphenyldiol are produced from the lowest temperature and reach a maximum at $748 \mathrm{~K}$. The combination of a methyl radical with the radical deriving from guaiacol can produce the first one, while the second one should come from ipso addition of hydroxyphenyl radicals. Other 
phenolic are produced at higher temperature. 2-Methylbenzofurane fraction is maximum at 130 ppm at $848 \mathrm{~K}$, and $\mathrm{C}_{9} \mathrm{H}_{8} \mathrm{O}$ is close to 180 ppm at $798 \mathrm{~K}$. The structure of $\mathrm{C}_{9} \mathrm{H}_{8} \mathrm{O}$ could not be completely resolved. GC-MS analysis (mass spectra is displayed in figure S5 in SM) exhibits a molecular mass of 132 corresponding to $\mathrm{C}_{9} \mathrm{H}_{8} \mathrm{O}$ or $\mathrm{C}_{8} \mathrm{H}_{4} \mathrm{O}_{2}$. This latter could be bicyclo[4.2.0]octa-1,3,5-triene-7,8-dione but the mass spectra mismatched and the most probable formula remained $\mathrm{C}_{9} \mathrm{H}_{8} \mathrm{O}$. The presence of peaks of $\mathrm{m} / \mathrm{z} 104$ and 78 indicates the possibility of a loss of $\mathrm{CO}$ and the presence of an aromatic ring. Possible structures are then dihydrobenzopyrane of 2-indanone. Note that 1-indanone and cinnamaldehyde were injected in GC but did not fit retention time of the reaction products.
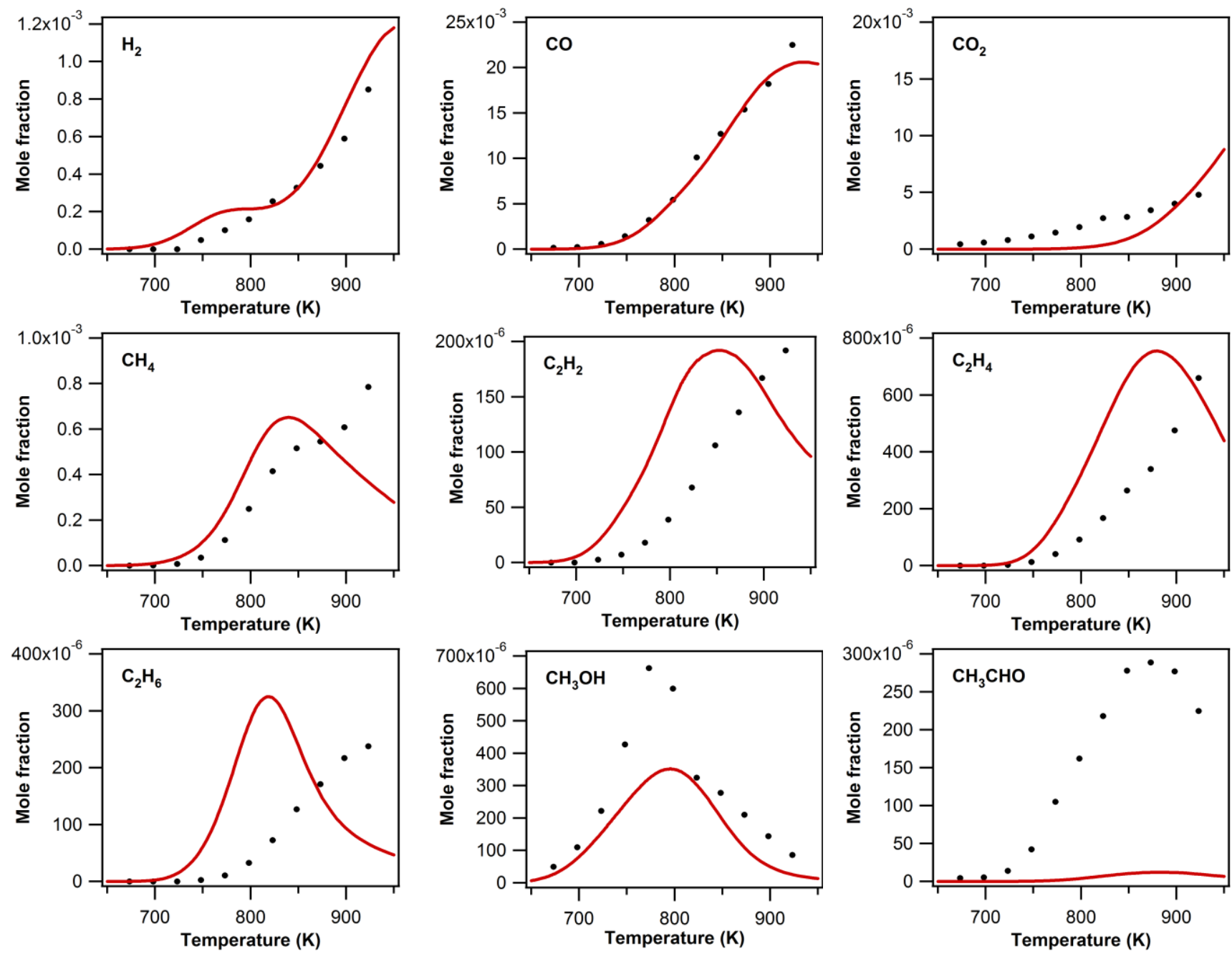
Figure 7. Evolution of mole fractions of light $\mathrm{C}_{0}-\mathrm{C}_{2}$ products during the oxidation of guaiacol.
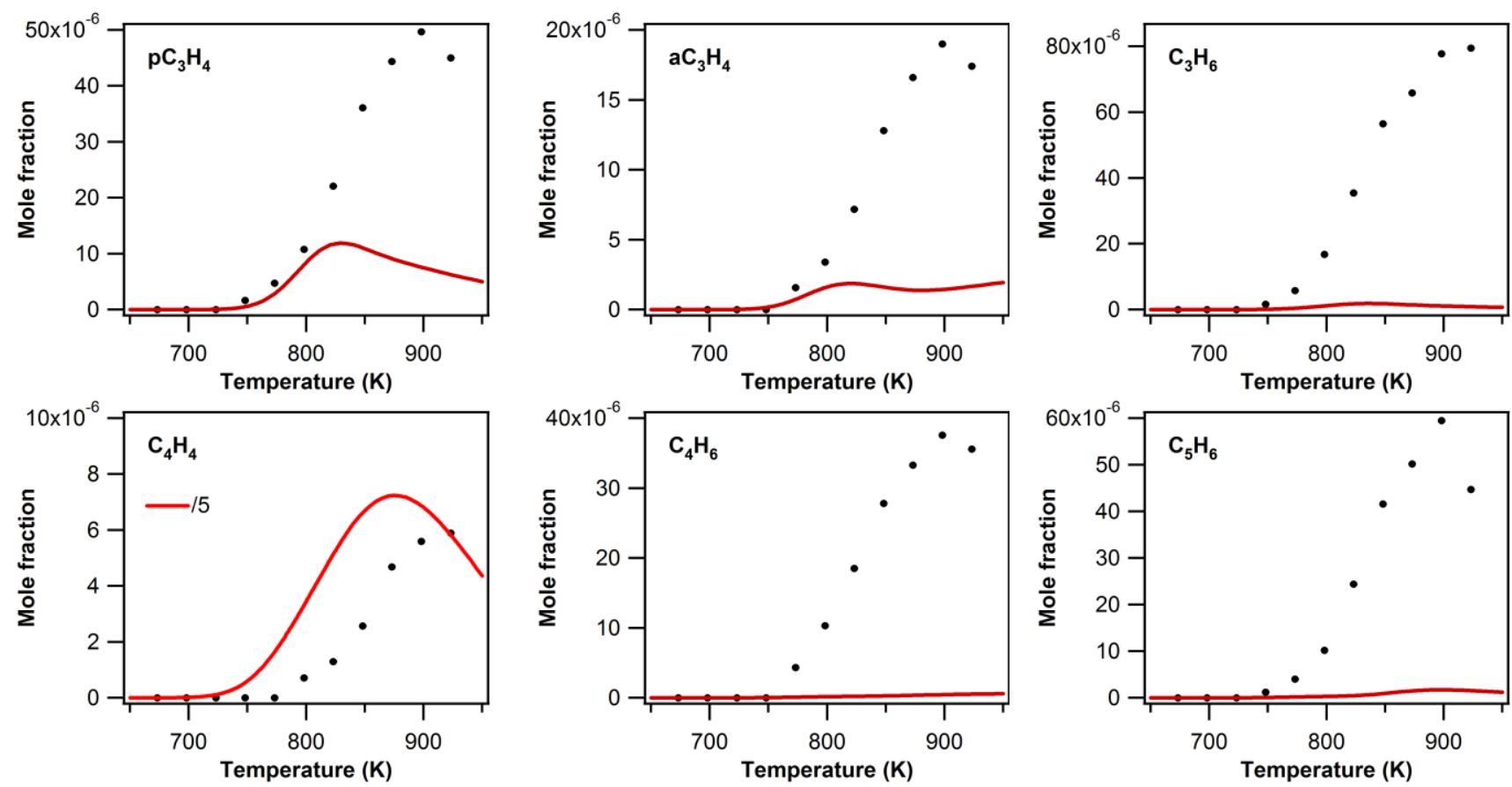

Figure 8. Evolution of mole fractions of some $\mathrm{C}_{3}-\mathrm{C}_{5}$ hydrocarbons during the oxidation of guaiacol.
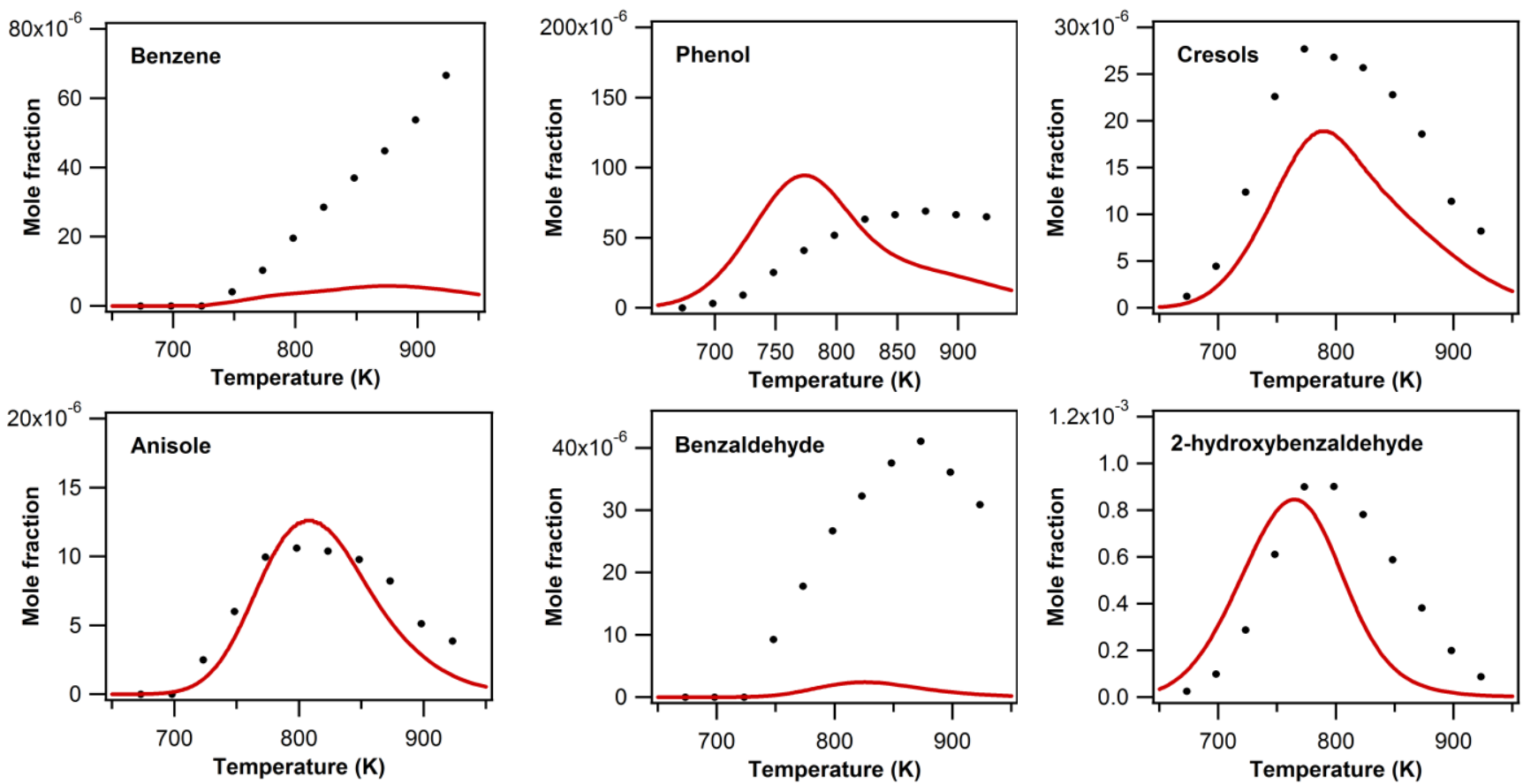

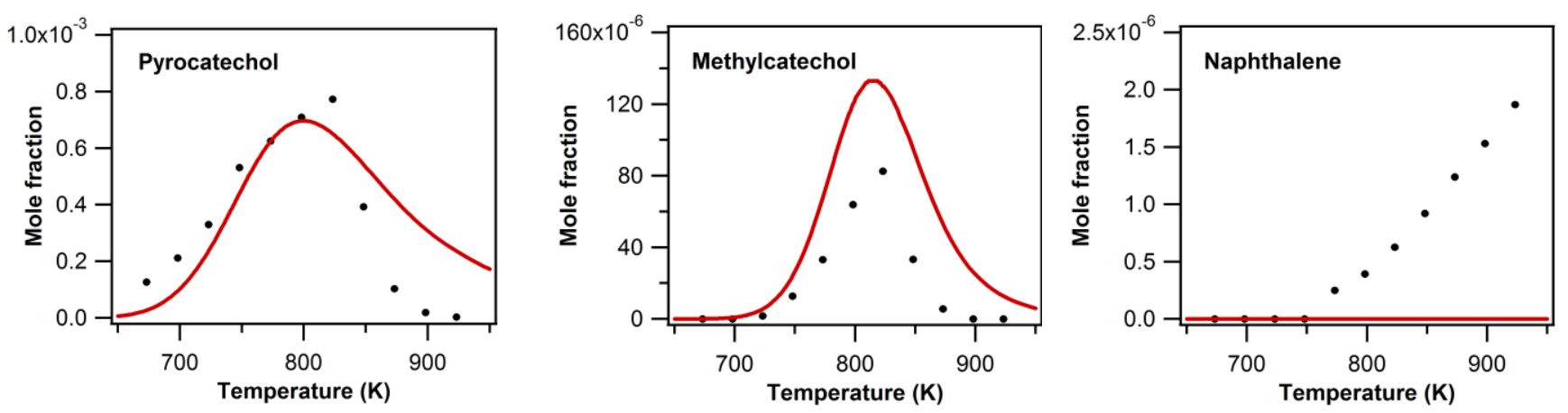

Figure 9. Evolution of mole fractions of main aromatic products during the oxidation of guaiacol.

\section{Comparison of experiments and simulations}

The detailed kinetic mechanism developed in this work correctly represents the conversion of guaiacol in pyrolysis (Figure 2). The model reproduces fairly well the experimental profiles of light species (figure 3), except the amount of acetylene at the highest temperatures. Hydrogen $\mathrm{H}_{2}$ looks overestimated between $600 \mathrm{~K}$ and $800 \mathrm{~K}$, indicating that reactions of metathesis between $\mathrm{H}$-atom and guaiacol may be too fast at low temperature. On the other hand, the experimental amount of $\mathrm{H}_{2}$ in this range of temperature is below the detection threshold of 100 ppm. The profile of methane, which is yielded mainly by $\mathrm{H}$-atom abstraction by $\mathrm{CH}_{3}$ radicals, is well estimated by the model, as well as ethane, the most abundant compound among the $\mathrm{C}_{2}$ hydrocarbons, which is just slightly overestimated at the highest temperatures. Ethylene and acetylene, in smaller quantities, are not as well predicted by the model. In particular, $\mathrm{C}_{2} \mathrm{H}_{2}$ is overestimated by a factor 2 at $850 \mathrm{~K}$ and 6 at $900 \mathrm{~K}$ due to the globalization of some reactions of decomposition of heavier unsaturated species, e.g. $\mathrm{C}_{5} \mathrm{H}_{4} \mathrm{OH}$, which is produced by the decomposition of $\mathrm{OC}_{6} \mathrm{H}_{4} \mathrm{OH}$ radicals. This latter are directly produced by the break of the methoxy bond in guaiacol.

Among the $\mathrm{C}_{3}-\mathrm{C}_{5}$ compounds (figure 4), propene and propane are fairly reproduced, even if the latter is overestimated at high temperature, and the major $\mathrm{C}_{4}$ hydrocarbon, vinylacetylene, is well 
reproduced by the model. 1-Butene $\mathrm{C}_{4} \mathrm{H}_{8}$ and 1,3-butadiene $\mathrm{C}_{4} \mathrm{H}_{6}$ are underestimated but remain to low levels. Eventually, the model underestimates also cyclopentadiene, which is formed experimentally from $800 \mathrm{~K}$ and from $900 \mathrm{~K}$ in simulation. Note that the model includes usual reaction routes of formation of cyclopentadiene from $\mathrm{C}_{1}-\mathrm{C}_{4}$ hydrocarbons and radicals, and that the prediction of most important light species is globally correct, but these reactions are relatively slow at the studied temperatures. It looks like that the formation pathways of cyclopentadiene would come from aromatic intermediates. On the other hand, the structure of guaiacol and of the main aromatic products, which involves two oxygenated functions, did not permit to find an obvious reaction channel able to account for the somewhat important amount of $\mathrm{C}_{5} \mathrm{H}_{6}$ produced at relatively low temperature.

The model reproduces well the aromatic compounds (figure 5), which are the main reaction primary products. The formation of pyrocatechol is underestimated by a factor of 2 , but the location of the maximum is correctly estimated by the model. Note also that the experimental mole fraction of this compound suffers from large uncertainty, around $\pm 25 \%$, as discussed above, due to its high reactivity and dramatic wall adsorption in the sampling lines. The quantities of methylcatechols and 2-hydroxybenzaldehyde are very well reproduced by the model. Among minor phenolic products, cresols are perfectly reproduced by the kinetic model below $800 \mathrm{~K}$, while phenol, which is formed mainly by the decomposition of $\mathrm{HOC}_{6} \mathrm{H}_{4} \mathrm{CH}_{2} \mathrm{O}$ radicals into phenol and $\mathrm{CHO}$ radicals, is overestimated. The small amount of anisole is slightly underestimated by the model, but the shape of the simulated profile is correct. Note that two minor products, 2-ethylphenol and 2,3-dihydrobenzofuran (figure S2), were not included in the model.

In oxidation, the conversion of guaiacol is perfectly predicted by the model, as well as that of oxygen (Figure 6). Carbon monoxide, by far the major light product (Figure 7), is also well represented, whereas the model does not properly catch the experimental profile of carbon 
dioxide below $850 \mathrm{~K}$, where an early formation of $\mathrm{CO}_{2}$ has been experimentally detected. Oxidation of $\mathrm{CO}$ by hydroxyl radicals is too slow in these conditions to account for it; reactions specific to phenolic or cyclic oxygenated intermediates or heterogeneous reactions may be involved. The methane profile is well reproduced up to about $860 \mathrm{~K}$ but decreases at higher temperature conversely to experimental data. The same trends are observed for $\mathrm{C}_{2}$ hydrocarbons. It appears that the model somewhat over-predicts the reactivity of hydrocarbon intermediates above $850 \mathrm{~K}$, the temperature corresponding to a total consumption of guaiacol. Among light oxygenated products, the model reproduced well the early formation of methanol, which is produced by $\mathrm{H}$-atom abstractions from guaiacol by methoxy radicals, but underestimates the peak amount. Acetaldehyde, produced at higher temperature, is strongly overestimated. Except $\mathrm{C}_{4} \mathrm{H}_{4}$, which is overestimated by a factor five, $\mathrm{C}_{3}-\mathrm{C}_{4}$ hydrocarbons are strongly underpredicted by the model. These species are produced in small amounts likely by missing decomposition reactions of aromatic rings, which are largely unknown for phenolic compounds in these low temperature conditions, at which aromatics as benzene or toluene are mostly unreactive.

As in pyrolysis, the primary phenolic species, pyrocatechol, 2-hydroxybenzaldehyde and methylcatechols, are well reproduced by the model, as well as anisole and cresols. Phenol is overestimated in the low temperature range of the study. This species is formed by a decomposition of $\mathrm{HOC}_{6} \mathrm{H}_{4} \mathrm{CH}_{2} \mathrm{O}$ radicals, in competition with the formation of 2hydroxybenzaldehyde. Rate parameters were adapted from that evaluated theoretically for the equivalent reaction of $\mathrm{C}_{6} \mathrm{H}_{4} \mathrm{CH}_{2} \mathrm{O}$ radical ${ }^{59}$ and may be affected by the presence of the hydroxyl group. Benzaldehyde, whose mole fraction is underestimated, comes solely from the decomposition of anisole in the model.

Benzene and naphthalene, which are the only non-oxygenated aromatics experimentally detected, are not correctly predicted by this model. Benzene is mainly produced in simulations by ipso addition of $\mathrm{H}$-atoms on phenol and from reactions from methylcyclopentadiene. The 
underestimation of benzene and naphthalene is certainly linked to the underestimation of the concentration of the $\mathrm{C}_{5} \mathrm{H}_{5}$ radicals, which are among the main precursors of these two products. In the mechanism, there is probably a lack of reaction pathway other than ipso-additions to eliminate the oxygen atoms involved in guaiacol. As a consequence the formation of $\mathrm{C}_{5} \mathrm{H}_{5}$ and $\mathrm{C}_{5} \mathrm{H}_{6}$ is not favored, as simulations show in both pyrolysis and combustion. Note that $\mathrm{C}_{2}-\mathrm{C}_{4}$ reaction routes of formation of aromatic rings, such as propargyl $\mathrm{C}_{3} \mathrm{H}_{3}$ radical combination, are included in the model but are of very minor importance in the temperature range of this study.

To summarized, the model developed in this work predicts accurately the conversion of guaiacol and the formation of the main aromatic products, as well as light species in both thermal decomposition and combustion. On the other hand, the prediction of minor $\mathrm{C}_{3}-\mathrm{C}_{5}$ intermediates, which are likely decomposition products of aromatic rings, is often defective. The model quality deteriorates also at the highest studied temperatures, corresponding to a full conversion of guaiacol. The chemistry of primary reaction products, mainly pyrocatechol and methylcatechol have still to be unraveled. The rate constants for their reactions, especially $\mathrm{H}$-atom abstractions and unimolecular decompositions, would benefit from further theoretical investigations. The decomposition of pyrocatechol leads especially to o-benzoquinone and $\mathrm{C}_{5} \mathrm{H}_{4} \mathrm{OH}$ radicals, producing thereafter large yields of cyclopentadienone and $\mathrm{C}_{5} \mathrm{H}_{5} \mathrm{OH}$, which chemistry is mostly unknown. The decomposition routes of radicals produced from these latter species would also require further experimental and theoretical studies.

\section{Analysis and discussion}

\section{Reactions routes of guaiacol}

The model allows analyzing guaiacol decomposition routes in pyrolysis and in oxidation. The main routes of consumption of guaiacol in thermal decomposition at $748 \mathrm{~K}$ are displayed in Figure 10. The conversion rate of the reactant is $17 \%$ at this temperature. The major 
decomposition route is the unimolecular break of the $\mathrm{O}-\mathrm{CH}_{3}$ bond, which accounts for $58 \%$ of the consumption flux. This reaction produces $\mathrm{OC}_{6} \mathrm{H}_{4} \mathrm{OH}$ and methyl radicals. Subsequently, $\mathrm{OC}_{6} \mathrm{H}_{4} \mathrm{OH}$ can react with methyl to give the methylcatechols $\left(11 \%\right.$ of $\mathrm{OC}_{6} \mathrm{H}_{4} \mathrm{OH}$ consumption flux) or else forms pyrocatechol by either the combination with a hydrogen atom or an $\mathrm{H}$-atom abstraction from guaiacol or methylcatechols ( $89 \%$ of the reaction flow). The second pathway of consumption of guaiacol is the $\mathrm{H}$-atom abstraction from the hydroxyl group yielding $\mathrm{OC}_{6} \mathrm{H}_{4} \mathrm{OCH}_{3}$ radicals, which represents $32 \%$ of the consumption flux. In these conditions, the major abstracting radical is by far $\mathrm{OC}_{6} \mathrm{H}_{4} \mathrm{OH}$ radical, followed by $\mathrm{CH}_{3}$ radicals and $\mathrm{H}$-atoms. $\mathrm{H}$-atom abstraction from the methoxy group accounts only for $6 \%$ of guaiacol consumption because of the high energy of the $\mathrm{C}-\mathrm{H}$ bond compared to the $\mathrm{O}-\mathrm{H}$ bond (Figure 1). Note however that $\mathrm{OC}_{6} \mathrm{H}_{4} \mathrm{OCH}_{3}$ radicals isomerized totally to $\mathrm{OHC}_{6} \mathrm{H}_{4} \mathrm{OCH}_{2}$ radicals thanks to an internal $\mathrm{H}$-atom transfer through a 6-membered cyclic transition state. $\mathrm{OHC}_{6} \mathrm{H}_{4} \mathrm{OCH}_{2}$ radicals are then converted into $\mathrm{HOC}_{6} \mathrm{H}_{4} \mathrm{CH}_{2} \mathrm{O}$ to finally yield 2-hydroxybenzaldehyde (93\% of the reaction flow) and phenol (6\% of the reaction flow). Ipso-additions are involved in two minor reactions of consumption of guaiacol. The addition of $\mathrm{H}$-atoms and methyl radicals on the carbon atom of the aromatic ring bearing the methoxy group leads to the formation of phenol and o-cresol, respectively.

A higher reaction temperature increases the role of the unimolecular decomposition. An almost total conversion of guaiacol is reached at $873 \mathrm{~K}\left(99 \%\right.$ conversion). The break of the $\mathrm{O}-\mathrm{CH}_{3}$ bond accounts for $96 \%$ of guaiacol reaction, whereas $\mathrm{H}$-atom abstractions become minor. $\mathrm{OC}_{6} \mathrm{H}_{4} \mathrm{OH}$ radicals still lead to pyrocatechol (combination with $\mathrm{H}$-atom or $\mathrm{H}$-atom abstractions accounting for $27 \%$ of $\mathrm{OC}_{6} \mathrm{H}_{4} \mathrm{OH}$ flux) or react with methyl radicals to produce methylcatechols (34\% of $\mathrm{OC}_{6} \mathrm{H}_{4} \mathrm{OH}$ flux), but the main reaction channel is at this higher temperature a unimolecular decomposition (39\% of $\mathrm{OC}_{6} \mathrm{H}_{4} \mathrm{OH}$ flux). The loss of $\mathrm{CO}$ of the hydroxy phenoxy radical produces a hydroxyl cyclopentadienyl radical, which decomposes finally to cyclopentadienone $\mathrm{C}_{5} \mathrm{H}_{4} \mathrm{O}$. For even higher temperatures, chain reactions mechanism through $\mathrm{H}$-abstractions becomes negligible and the mechanism is summarized to the initial bond 
breaking followed by the decomposition of $\mathrm{OC}_{6} \mathrm{H}_{4} \mathrm{OH}$ radicals to $\mathrm{CO}$ and $\mathrm{C}_{5} \mathrm{H}_{4} \mathrm{OH}$, as observed by Scheer et $\mathrm{al}^{30}$.

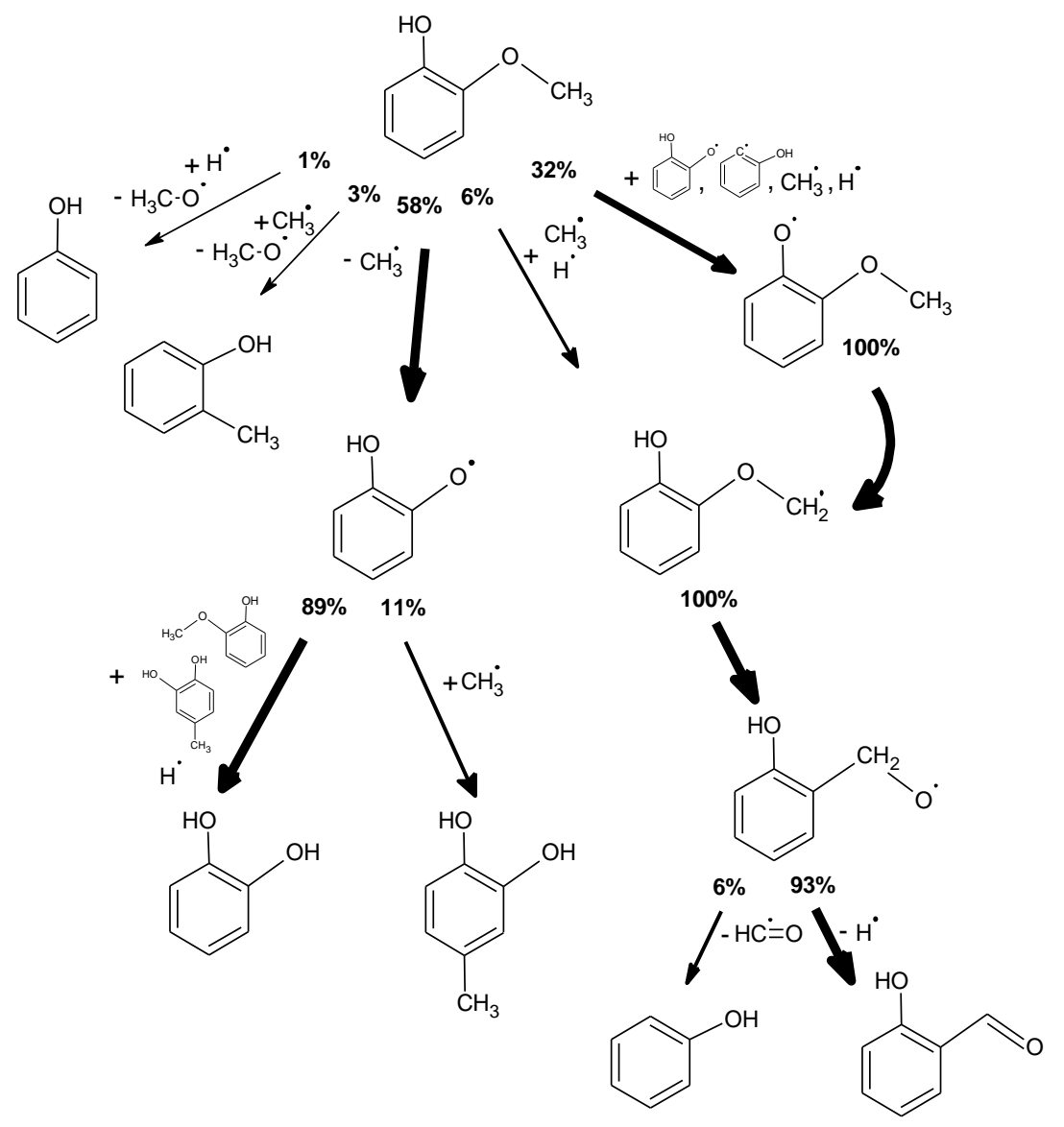

Figure 10. Reaction flux analysis for guaiacol pyrolysis. Conditions of simulation: $748 \mathrm{~K}, 800$ Torr, residence time of $2 \mathrm{~s}$ corresponding to $17 \%$ conversion. Reaction fluxes associated with arrows are relative to the consumption of a given species

The presence of oxygen enhances the conversion of guaiacol but main reaction channels remain the same for pyrolysis, as displayed in Figure 11. At $748 \mathrm{~K}$, guaiacol conversion reaches $36 \%$ in oxidation, as simulations. The proportion of the unimolecular decomposition decreases in favor of the of $\mathrm{H}$-atom abstractions in the radical chain mechanism. The $\mathrm{O}-\mathrm{C}$ bond breaking represents $38 \%$ of the consumption flux, whereas $\mathrm{H}$-atom abstractions yielding $\mathrm{OC}_{6} \mathrm{H}_{4} \mathrm{OCH}_{3}$ and 
$\mathrm{OHC}_{6} \mathrm{H}_{4} \mathrm{OCH}_{2}$ radicals represent respectively $40 \%$ and $20 \%$ of the flux. $\mathrm{OC}_{6} \mathrm{H}_{4} \mathrm{OH}$ radicals react according to three reaction paths. The first channel ( $60 \%$ of the flux) leads to the formation of the pyrocatechol, mainly by disproportionation with $\mathrm{HO}_{2}$ radicals, combination with $\mathrm{H}$-atom and in a lower extend by $\mathrm{H}$-atom abstraction from guaiacol. The second route, which was not present in pyrolysis, is the decomposition of $\mathrm{OC}_{6} \mathrm{H}_{4} \mathrm{OH}$ to ortho-benzoquinone by $\mathrm{H}$-atom abstraction by $\mathrm{O}_{2}$ or the $\mathrm{HO}_{2}$ radical (37\% of the flux). Subsequently, ortho-benzoquinone undergoes decomposition into cyclopentadienone which eventually breaks down into several light products. The third reaction of consumption of $\mathrm{OC}_{6} \mathrm{H}_{4} \mathrm{OH}$ radicals is the reaction with methyl radicals, which produces methylcatechol ( $2 \%$ of the flux). Concerning radicals produced by $\mathrm{H}$-atom abstraction from guaiacol, $\mathrm{OC}_{6} \mathrm{H}_{4} \mathrm{OCH}_{3}$ isomerizes into $\mathrm{OHC}_{6} \mathrm{H}_{4} \mathrm{OCH}_{2}$, while this latter isomerizes totally into $\mathrm{HOC}_{6} \mathrm{H}_{4} \mathrm{CH}_{2} \mathrm{O}$, as in pyrolysis. Eventually, the decomposition of $\mathrm{HOC}_{6} \mathrm{H}_{4} \mathrm{CH}_{2} \mathrm{O}$ is not really influenced by the presence of oxygen. This radical produces hydroxybenzaldehyde and phenol in the same proportion as in pyrolysis. As in pyrolysis, a higher temperature favors the unimolecular decomposition, which flux accounts for $94 \%$ at 873 $\mathrm{K}$, over the $\mathrm{H}$-atom abstractions. At this temperature, the fate of the hydroxyphenoxy radical $\mathrm{OC}_{6} \mathrm{H}_{4} \mathrm{OH}$ is still dominated by the decomposition into o-benzoquinone (54\% of its consumption), while the formation of pyrocatechol and that of methylcatechol represents $38 \%$ and $3 \%$ of the consumption, respectively. The loss of $\mathrm{CO}$ leading to hydroxyl cyclopentadienyl radical $\mathrm{C}_{5} \mathrm{H}_{4} \mathrm{OH}$ consumes only $5 \%$ of $\mathrm{OC}_{6} \mathrm{H}_{4} \mathrm{OH}$. To summarize, it appears that the presence of oxygen does not change deeply the reaction scheme of guaiacol in the studied temperature range. The main influence is the limited rise of the reactivity of guaiacol due to the enhancement of the radical pool, especially $\mathrm{OH}, \mathrm{HO}_{2}, \mathrm{CH}_{3} \mathrm{O}$, and $\mathrm{CH}_{3} \mathrm{OO}$, but the unimolecular decomposition of guaiacol remains the most important reaction pathway due to the fragility of the $\mathrm{O}-\mathrm{C}$ bond. Among product, the presence of $\mathrm{O}_{2}$ and oxygenated radicals favors the decomposition of $\mathrm{OC}_{6} \mathrm{H}_{4} \mathrm{OH}$ into o-benzoquinone over the formation of pyrocatechol, and as a consequence, a prompt formation of oxygenated $\mathrm{C}_{5}$ products. 


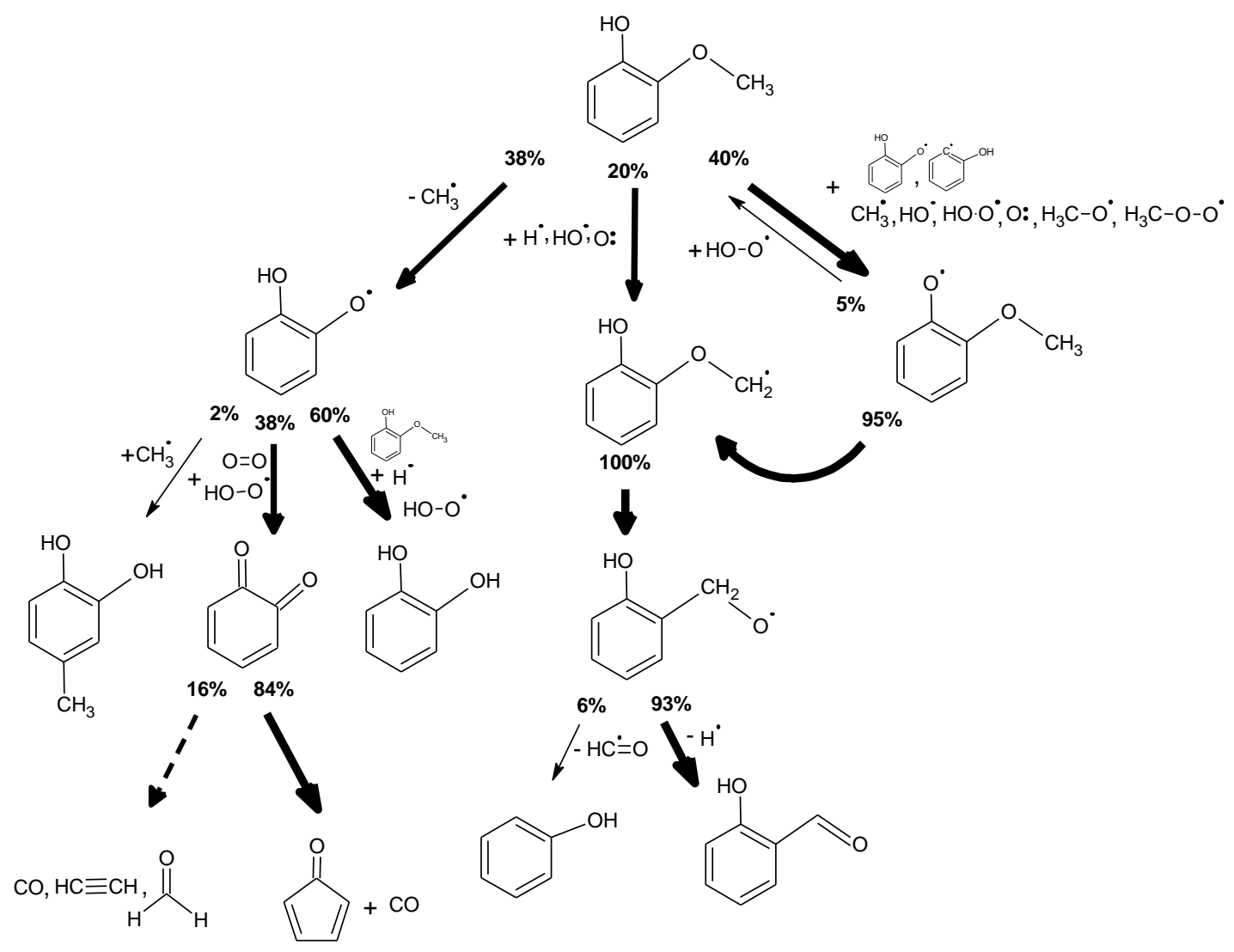

Figure 11. Reaction flux analysis for guaiacol oxidation. Conditions of simulation: $748 \mathrm{~K}, 800$ Torr, stoichiometric mixture, residence time of 2 s corresponding to $36 \%$ conversion. Reaction fluxes associated with arrows are relative to the consumption of a given species. The dash arrow summarizes some successive reactions.

A sensitivity analysis was performed in both pyrolysis and oxidation at moderate (748 K) and total $(873 \mathrm{~K})$ conversion, which results are summarized in Figure 12. The most promoting reaction rate is basically that of the unimolecular initiation breaking the $\mathrm{O}-\mathrm{C}$ bond. Note however that in pyrolysis at low temperature, the $\mathrm{H}$-abstraction by $\mathrm{OC}_{6} \mathrm{H}_{4} \mathrm{OH}$ radicals is more sensitive. At this temperature, this later radicals acts as a chain carrier in the radical mechanism and this $\mathrm{H}$-atom abstraction competes the inhibiting combination with $\mathrm{H}$-atom to produce pyrocatechol. When temperature increases in pyrolysis, the most promoting reactions are that consuming methyl and $\mathrm{OC}_{6} \mathrm{H}_{4} \mathrm{OH}$ radicals. These latter are indeed somewhat little reactive and 
tend to combine back to guaiacol. This equilibrium explains the relative lower sensitivity of the rate constant of the initial decomposition reaction. The formation of methylcatechol and the decomposition by loss of $\mathrm{CO}$ becomes the most promoting steps, as well as the combinations of methyl radicals to produce ethane. It is although interesting to note the promoting effect of this latter combination by removing methyl radicals, whereas this combination of free radical usually inhibits strongly radical chain reactions. In the same way, the combination of $\mathrm{H}$-atoms with $\mathrm{OC}_{6} \mathrm{H}_{4} \mathrm{OH}$ radicals is also slightly promoting in pyrolysis at high temperature by competing with the combination $\mathrm{OC}_{6} \mathrm{H}_{4} \mathrm{OH}$ with $\mathrm{CH}_{3}$, which yields back guaiacol. In oxidation, the chain radical mechanism plays a larger role and $\mathrm{H}$-atom abstractions from the reactant exhibit a little promoting effect, especially with oxygenated radicals. Conversely, $\mathrm{H}$-atom abstractions from pyrocatechol, which consume active radicals and produced the little reactive hydroxyl phenoxy radicals, inhibit the global reactivity. More sensitive are reactions of $\mathrm{HO}_{2}$ with small radicals: as usual in oxidation ${ }^{13,68}$, self-combination of this one inhibits the system whereas the reaction with methyl, which produces methoxy and hydroxyl radicals, promotes the reactivity. Eventually, reactions of formation of 0 -benzoquinone and of decomposition of this species enhance the reactivity by improving the formation of small species over little reactive phenolic radicals. 


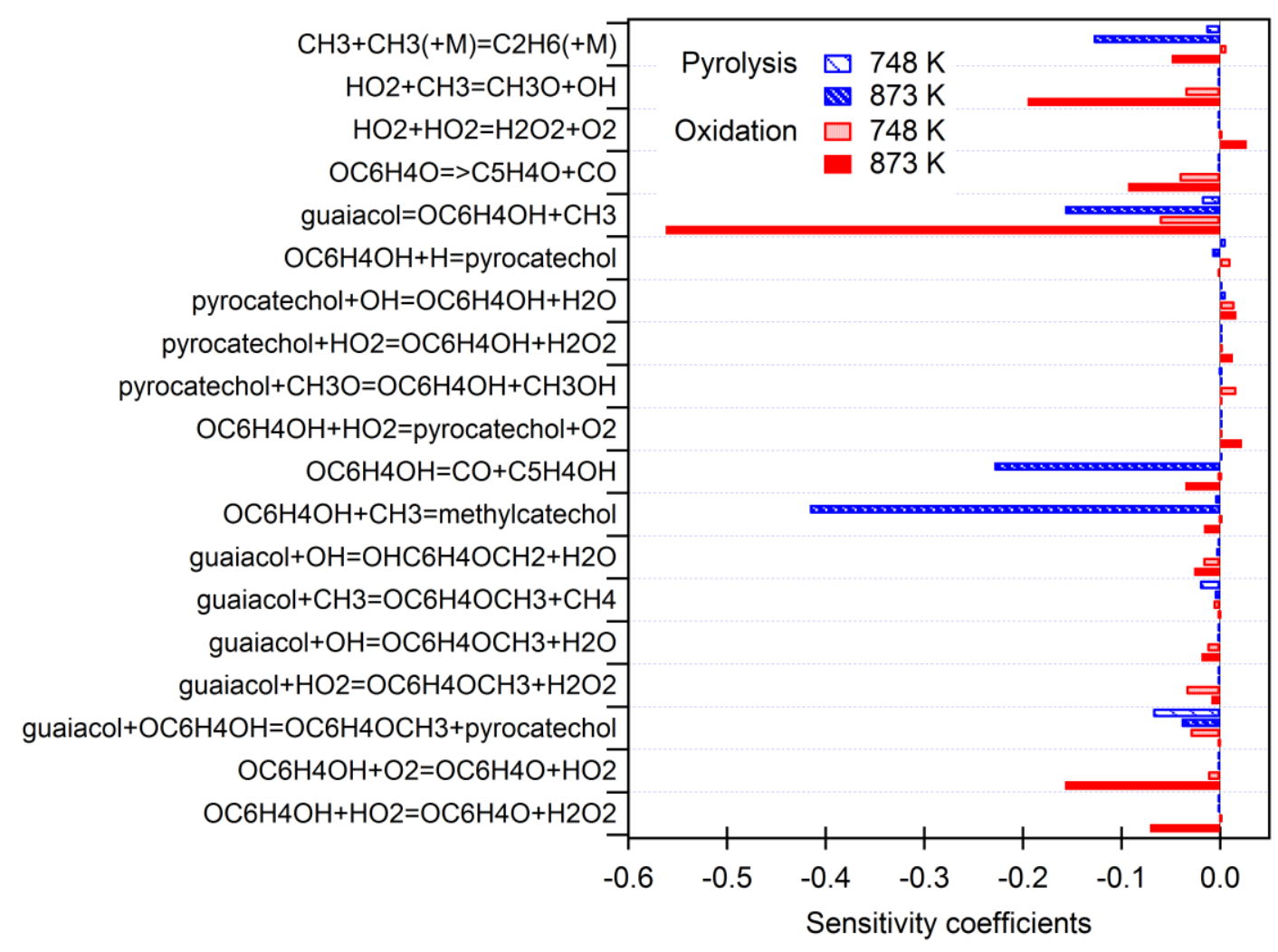

Figure 12. Sensitive reactions in the consumption of guaiacol during pyrolysis and stoichiometric oxidation at 748 and $873 \mathrm{~K}$.

\section{Comparison with anisole}

Anisole and guaiacol are model molecules of primary tars derived from lignin. Both molecules involve an aromatic ring bounded to a methoxy group, characteristic of lignin structure. The only difference between these molecules is the presence of the hydroxy group in the ortho position in guaiacol. Both molecules reacts by the breaking of the $\mathrm{O}-\mathrm{CH}_{3}$ bond at high temperature ${ }^{30,69}$. Experimental and theoretical results obtained for guaiacol can be compared to our previous study on anisole pyrolysis and oxidation. ${ }^{13}$ Figure 13 displays the experimental profiles of both phenolic molecules in pyrolysis and in oxidation, as well as a comparison during their oxidation of the production of benzene and naphthalene, which are typical tertiary tars formed in thermal treatments of biomass. 
The thermal decomposition of anisole starts at $750 \mathrm{~K}$ while that of guaiacol starts around $650 \mathrm{~K}$. A total conversion of anisole is achieved at $950 \mathrm{~K}$ against $900 \mathrm{~K}$ for guaiacol. The early decomposition of guaiacol compared to anisole is linked to weakness of the $\mathrm{O}-\mathrm{CH}_{3}$ bond, which dissociation energy drops from $65.6 \mathrm{kcal} \mathrm{mol}^{-1}$ in anisole to $58.1 \mathrm{kcal} \mathrm{mol}^{-1}$ in guaiacol. The same difference in reactivity between guaiacol and anisole is observed in oxidation, but the effect of oxygen compared to thermal decomposition looks more observable in the case of guaiacol. In figure 13 , oxidation shifts the profile of anisole towards lower temperatures by around $10 \mathrm{~K}$ compared to pyrolysis, whereas the shift is around $20 \mathrm{~K}$ in the case of guaiacol. The higher reactivity in oxidation compared to pyrolysis is due to the enhancement of the radical chain mechanism by oxygen to the detriment of the dominant unimolecular decomposition channel. Oxygen rises the amount of free radicals and especially reactive ones as $\mathrm{OH}$ and $\mathrm{CH}_{3} \mathrm{O}$, which can react by $\mathrm{H}$-atom abstraction with the reactant. The fragile $\mathrm{O}-\mathrm{H}$ bond in guaiacol (BDE $87.1 \mathrm{kcal} \mathrm{mol}^{-1}$ ) compared to methoxy group makes easier this chain radical mechanism in the case of guaiacol. The sensitivity of the $\mathrm{H}$-atom abstractions from guaiacol by $\mathrm{OH}$ and $\mathrm{HO}_{2}$ radicals appears in Figure 12.

Similarities are observed in the products of reaction of guaiacol and anisole. In both cases, an important formation of secondary tars of the phenolic family is obtained. The main primary products are phenol and cresols from the decomposition of anisole as well as pyrocatechol and methylcatechols from guaiacol. It is noteworthy that the pyrolysis of anisole led to the formation of tertiary tars such as benzene, naphthalene or acenaphthylene ${ }^{13}$, which were not detected during the pyrolysis of guaiacol. This can be explained by the presence of two oxygen atoms bounded to the aromatic ring in the latter species. Decomposition of anisole leads to phenoxy radicals, which decomposition produces cyclopentadienyl radicals that are HAP precursors. Conversely, guaiacol decomposition leads mostly to oxygenated cyclopentadienyl that would not favor the formation of hydrocarbons. As presented in Figure 13, both anisole and guaiacol form in oxidation tertiary tars, such as benzene and naphthalene. The former one leads to higher 
yields of aromatics, but guaiacol shows a lightly earlier formation of benzene due to the reactivity of this molecule at lower temperature than anisole. As discussed above, the early formation of benzene and naphthalene in oxidation cannot be explained by usual high temperature mechanisms based on acetylene, propargyl or cyclopentadienyl radicals, which were developed in flame conditions. ${ }^{59}$ Light unsaturated intermediates are indeed in too small quantities to account for the formation of aromatic rings through these reactions. On the other hand, it appears that these tertiary tars are produced in much little quantities is the case of guaiacol compared to anisole, the former being the main phenolic intermediate really quantified in lignin thermal reactions ${ }^{14,16}$
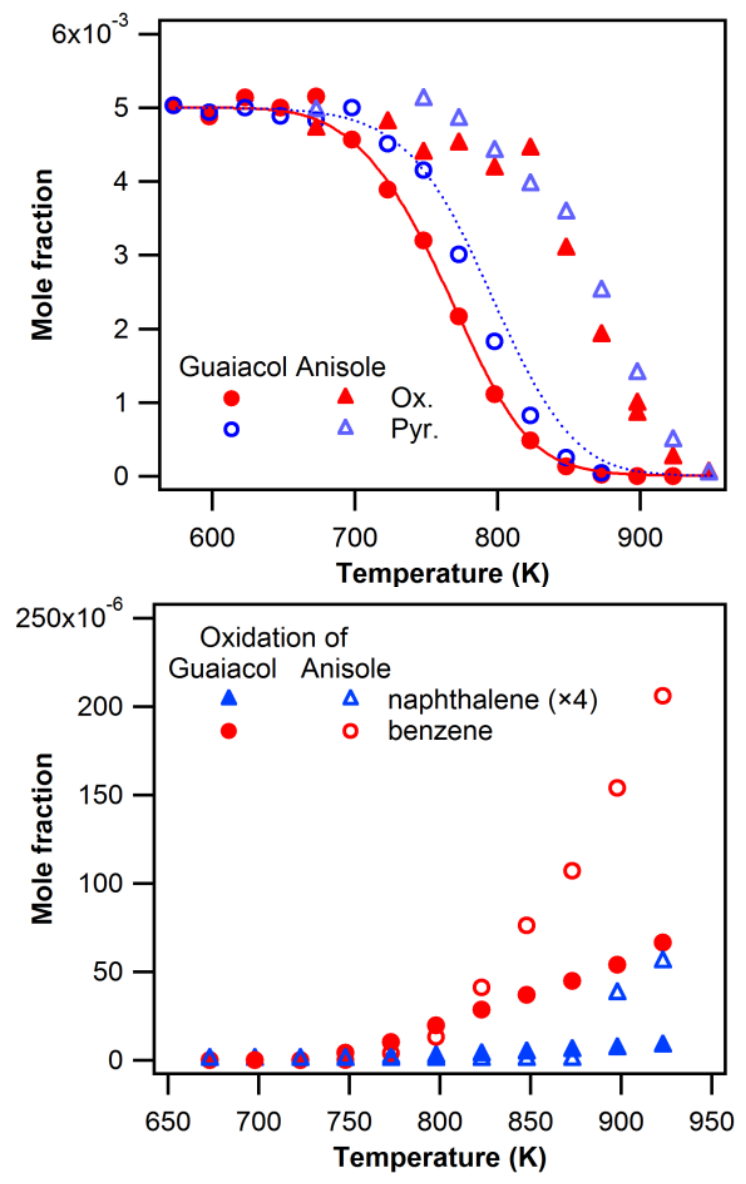

Figure 13. Comparison of pyrolysis and oxidation of guaiacol and anisole. Top: mole fraction of reactants (mole fraction of anisole in pyrolysis is divided by 2 for an easier comparison ${ }^{13}$ ); 
bottom: mole fractions of benzene and naphthalene during the stoichiometric oxidation of benzene and naphthalene.

\section{Conclusion}

Thermal treatment of biomass generates hundreds of primary tar from wood component, i.e. cellulose, hemicelluloses and lignin. These species are further converted in the gas phase towards species with lower $\mathrm{O} / \mathrm{C}$ and $\mathrm{H} / \mathrm{C}$ ratios during the so-called tar maturation. Guaiacol is one of the main compounds among the numerous methoxy phenols produced from lignin and can be considered as a representative surrogate of lignin primary tars. Its pyrolysis and stoichiometric oxidation were studied in a jet-stirred reactor, in order to assess its reactivity and product distribution. A first detailed kinetic model has been developed, which successfully reproduces the reactant consumption and the profiles of the main products over the studied temperature range. It was shown that the reaction of guaiacol is dominated in both pyrolysis and oxidation by the unimolecular decomposition breaking the weak $\mathrm{O}-\mathrm{C}$ bond of the methoxy group. Chain radical mechanism is less important, except at the lowest temperatures of the study. The presence of the fragile phenolic $\mathrm{O}-\mathrm{H}$ bond favors however the chain radical mechanisms compared to anisole, and explained also the more promoting effect of the addition of oxygen compared to this latter methoxyphenol. The main primary products are phenolic molecules as pyrocatechol and methylcatechols, which are secondary tars. Further reactions of decomposition of the primary products lead mainly in the model to oxygenated $\mathrm{C}_{5}$ unsaturated compounds, such as cyclopentadienone or hydrocycyclopentadiene. The large uncertainty about the chemistry of these intermediates and about poly-substituted phenols makes further investigations on this 
species essential to unravel the full mechanism of decomposition of guaiacol and of other methoxy phenols issued from biomass.

\section{Supplemental information}

The supplemental material contains the nomenclature of species involved in the mechanism, experimental profiles of minor products quantified in pyrolysis and oxidation, which are not simulated by the model, the experimental mass spectra of the undetermined product of formula $\mathrm{C}_{9} \mathrm{H}_{8} \mathrm{O}$ and the kinetic mechanism.

\section{Acknowledgements}

This work was partially supported by the French ANR agency through the project "GAMECO" and the CNRS through the "CRAKIN" project. 


\section{References}

(1) Demirbas, A. Potential Applications of Renewable Energy Sources, Biomass Combustion Problems in Boiler Power Systems and Combustion Related Environmental Issues. Progress in Energy and Combustion Science 2005, 31, 171-192.

(2) Heringa, M. F.; DeCarlo, P. F.; Chirico, R.; Lauber, A.; Doberer, A.; Good, J.; Nussbaumer, T.; Keller, A.; Burtscher, H.; Richard, A.; et al. Time-Resolved Characterization of Primary Emissions from Residential Wood Combustion Appliances. Environ. Sci. Technol. 2012, 46, 11418-11425.

(3) Di Blasi, C. Modeling Chemical and Physical Processes of Wood and Biomass Pyrolysis. Progress in Energy and Combustion Science 2008, 34, 47-90.

(4) Williams, A.; Jones, J. M.; Ma, L.; Pourkashanian, M. Pollutants from the Combustion of Solid Biomass Fuels. Progress in Energy and Combustion Science 2012, 38, 113-137.

(5) Evans, R. J.; Milne, T. A. Molecular Characterization of the Pyrolysis of Biomass. Energy \& Fuels 1987, 1, 123-137.

(6) Anis, S.; Zainal, Z. A. Tar Reduction in Biomass Producer Gas via Mechanical, Catalytic and Thermal Methods: A Review. Renewable and Sustainable Energy Reviews 2011, 15 , 2355-2377.

(7) Font Palma, C. Modelling of Tar Formation and Evolution for Biomass Gasification: A Review. Applied Energy 2013, 111, 129-141.

(8) Hiblot, H.; Ziegler-Devin, I.; Fournet, R.; Glaude, P. A. Steam Reforming of Methane in a Synthesis Gas from Biomass Gasification. International Journal of Hydrogen Energy 2016, 41, 18329-18338.

(9) Bulushev, D. A.; Ross, J. R. H. Catalysis for Conversion of Biomass to Fuels via Pyrolysis and Gasification: A Review. Catalysis Today 2011, 171, 1-13.

(10) Shen, Y.; Yoshikawa, K. Recent Progresses in Catalytic Tar Elimination during Biomass Gasification or Pyrolysis-A Review. Renewable and Sustainable Energy Reviews 2013, 21, 371-392.

(11) Jegers, H. E.; Klein, M. T. Primary and Secondary Lignin Pyrolysis Reaction Pathways. Ind. Eng. Chem. Proc. Des. Dev. 1985, 24, 173-183.

(12) Dufour, A.; Weng, J.; Jia, L.; Tang, X.; Sirjean, B.; Fournet, R.; Gall, H. L.; Brosse, N.; Billaud, F.; Mauviel, G.; et al. Revealing the Chemistry of Biomass Pyrolysis by Means of Tunable Synchrotron Photoionisation-Mass Spectrometry. RSC Adv. 2013, 3, 4786-4792.

(13) Nowakowska, M.; Herbinet, O.; Dufour, A.; Glaude, P.-A. Detailed Kinetic Study of Anisole Pyrolysis and Oxidation to Understand Tar Formation during Biomass Combustion and Gasification. Combustion and Flame 2014, 161, 1474-1488.

(14) Dorrestijn, E.; Laarhoven, L. J. J.; Arends, I. W. C. E.; Mulder, P. The Occurrence and Reactivity of Phenoxyl Linkages in Lignin and Low Rank Coal. Journal of Analytical and Applied Pyrolysis 2000, 54, 153-192.

(15) De Wild, P. J.; Huijgen, W. J. J.; Heeres, H. J. Pyrolysis of Wheat Straw-Derived Organosolv Lignin. Journal of Analytical and Applied Pyrolysis 2012, 93, 95-103. 
(16) Hosoya, T.; Kawamoto, H.; Saka, S. Secondary Reactions of Lignin-Derived Primary Tar Components. Journal of Analytical and Applied Pyrolysis 2008, 83, 78-87.

(17) Hu, J.; Shen, D.; Xiao, R.; Wu, S.; Zhang, H. Free-Radical Analysis on Thermochemical Transformation of Lignin to Phenolic Compounds. Energy \& Fuels 2012, 27, 285-293.

(18) Olcese, R.; Carré, V.; Aubriet, F.; Dufour, A. Selectivity of Bio-Oils Catalytic Hydrotreatment Assessed by Petroleomic and GC* GC/MS-FID Analysis. Energy and Fuels 2013, 27, 2135-2145.

(19) Olcese, R. N.; Lardier, G.; Bettahar, M.; Ghanbaja, J.; Fontana, S.; Carré, V.; Aubriet, F.; Petitjean, D.; Dufour, A. Aromatic Chemicals by Iron-Catalyzed Hydrotreatment of Lignin Pyrolysis Vapor. ChemSusChem 2013, 6, 1490-1499.

(20) Elliott, D. C.; Hart, T. R. Catalytic Hydroprocessing of Chemical Models for Bio-Oil. Energy \& Fuels 2009, 23, 631-637.

(21) Jia, L.; Le Brech, Y.; Mauviel, G.; Qi, F.; Bente-von Frowein, M.; Ehlert, S.; Zimmermann, R.; Dufour, A. Online Analysis of Biomass Pyrolysis Tar by Photoionization Mass Spectrometry. Energy Fuels 2016, 30, 1555-1563.

(22) Jia, L.; Dufour, A.; Le Brech, Y.; Authier, O.; Mauviel, G. On-Line Analysis of Primary Tars from Biomass Pyrolysis by Single Photoionization Mass Spectrometry: Experiments and Detailed Modelling. Chemical Engineering Journal 2017, 313, 270-282.

(23) Olcese, R.; Bettahar, M. M.; Malaman, B.; Ghanbaja, J.; Tibavizco, L.; Petitjean, D.; Dufour, A. Gas-Phase Hydrodeoxygenation of Guaiacol over Iron-Based Catalysts. Effect of Gases Composition, Iron Load and Supports (Silica and Activated Carbon). Applied Catalysis B: Environmental 2013, 129, 528-538.

(24) Klein, M. T.; Virk, P. S. Model Pathways for Gas Release from Lignites. American Chemical Society Division of Fuel Chemistry Preprints 1980, 25, 180.

(25) Ceylan, R.; Bredenberg, J. B. Hydrogenolysis and Hydrocracking of the CarbonOxygen Bond. 2. Thermal Cleavage of the Carbon-Oxygen Bond in Guaiacol. Fuel 1982, 61, 377-382.

(26) Lawson, J. R.; Klein, M. T. Influence of Water on Guaiacol Pyrolysis. Industrial \& engineering chemistry fundamentals 1985, 24, 203-208.

(27) Vuori, A. Pyrolysis Studies of Some Simple Coal Related Aromatic Methyl Ethers. Fuel 1986, 65, 1575-1583.

(28) Vuori, A. I.; Bredenberg, J. B. -so. Thermal Chemistry Pathways of Substituted Anisoles. Industrial \& engineering chemistry research 1987, 26, 359-365.

(29) Parkhurst Jr, H. J.; Huibers, D. T. A.; Jones, M. W. Production of Phenol from Lignin. Am. Chem. Soc., Div. Pet. Chem., Prepr.;(United States) 1980, 25 (CONF800814-P1).

(30) Scheer, A. M.; Mukarakate, C.; Robichaud, D. J.; Nimlos, M. R.; Ellison, G. B. Thermal Decomposition Mechanisms of the Methoxyphenols: Formation of Phenol, Cyclopentadieneone, Vinylacetylene and Acetylene. The Journal of Physical Chemistry A 2011, 115, 13381-13389.

(31) Ormond, T. K.; Baraban, J. H.; Porterfield, J. P.; Scheer, A. M.; Hemberger, P.; Troy, T. P.; Ahmed, M.; Nimlos, M. R.; Robichaud, D. J.; Daily, J. W.; et al. Thermal Decompositions of the Lignin Model Compounds: Salicylaldehyde and Catechol. J. Phys. Chem. A 2018, 122, 5911-5924. 
(32) Coeur-Tourneur, C.; Cassez, A.; Wenger, J. C. Rate Coefficients for the GasPhase Reaction of Hydroxyl Radicals with 2-Methoxyphenol (Guaiacol) and Related Compounds. Journal of Physical Chemistry A 2010, 114, 11645-11650.

(33) Lauraguais, A.; Coeur-Tourneur, C.; Cassez, A.; Deboudt, K.; Fourmentin, M.; Choel, M. Atmospheric Reactivity of Hydroxyl Radicals with Guaiacol (2Methoxyphenol), a Biomass Burning Emitted Compound: Secondary Organic Aerosol Formation and Gas-Phase Oxidation Products. Atmospheric Environment 2014, 86, 155-163.

(34) Yang, B.; Zhang, H.; Wang, Y.; Zhang, P.; Shu, J.; Sun, W.; Ma, P. Experimental and Theoretical Studies on Gas-Phase Reactions of NO3 Radicals with Three Methoxyphenols: Guaiacol, Creosol, and Syringol. Atmospheric Environment 2016, 125, 243-251.

(35) Biet, J.; Hakka, M. H.; Warth, V.; Glaude, P.-A.; Battin-Leclerc, F. Experimental and Modeling Study of the Low-Temperature Oxidation of Large Alkanes. Energy Fuels 2008, 22, 2258-2269.

(36) Hakka, M. H.; Glaude, P. A.; Herbinet, O.; Battin-Leclerc, F. Experimental Study of the Oxidation of Large Surrogates for Diesel and Biodiesel Fuels. Combustion and Flame 2009, 156, 2129-2144.

(37) Hakka, M. H.; Bennadji, H.; Biet, J.; Yahyaoui, M.; Sirjean, B.; Warth, V.; Coniglio, L.; Herbinet, O.; Glaude, P. A.; Billaud, F.; et al. Oxidation of Methyl and Ethyl Butanoates. Int. J. Chem. Kinet. 2010, 42, 226-252.

(38) Glaude, P. A.; Herbinet, O.; Bax, S.; Biet, J.; Warth, V.; Battin-Leclerc, F. Modeling of the Oxidation of Methyl Esters-Validation for Methyl Hexanoate, Methyl Heptanoate, and Methyl Decanoate in a Jet-Stirred Reactor. Combustion and Flame 2010, 157, 2035-2050.

(39) Hakka, H. M.; Cracknell, R. F.; Pekalski, A.; Glaude, P.-A.; Battin-Leclerc, F. Experimental and Modeling Study of Ultra-Rich Oxidation of $\mathrm{n}$-Heptane. Fuel 2015, 144, 358-368.

(40) Tranchant, J.; Gardais, J. F.; Gorin, P.; Serpinet, J.; Untz, G. Manuel Pratique de Chromatographie En Phase Gazeuse; Masson: Paris, 1982.

(41) Husson, B.; Ferrari, M.; Herbinet, O.; Ahmed, S. S.; Glaude, P.-A.; Battin-Leclerc, F. New Experimental Evidence and Modeling Study of the Ethylbenzene Oxidation. Proceedings of the Combustion Institute 2013, 34, 325-333.

(42) Herbinet, O.; Husson, B.; Ferrari, M.; Glaude, P.-A.; Battin-Leclerc, F. Low Temperature Oxidation of Benzene and Toluene in Mixture with N-Decane. Proceedings of the Combustion Institute 2013, 34, 297-305.

(43) Montgomery, J.; Frisch, M. J.; Ochterski, J. W.; Petersson, G. A. A Complete Basis Set Model Chemistry. VI. Use of Density Functional Geometries and Frequencies. The Journal of Chemical Physics 1999, 110, 2822-2827.

(44) Frisch, M.; Trucks, G.; Schlegel, H.; Scuseria, G.; Robb, M.; Cheeseman, J.; Scalmani, G.; Barone, V.; Mennucci, B.; Petersson, G.; et al. Gaussian 09 Revision B.01; Gaussian, Inc: Wallingford CT, 2009.

(45) Petersson, G. A.; Malick, D. K.; Wilson, W. G.; Ochterski, J. W.; Jr, J. A. M.; Frisch, M. J. Calibration and Comparison of the Gaussian-2, Complete Basis Set, and Density Functional Methods for Computational Thermochemistry. The Journal of Chemical Physics 1998, 109, 10570-10579. 
(46) Cox, J. D.; Wagman, D. .; Medvedev, V. A. CODATA Key Values for Thermodynamics; Hemisphere: New York, 1989.

(47) Mokrushin, V.; Tsang, W. Chemrate v.1.5.2; NIST, Ed. Gaithersburg, MD 20899, U.S.A., 2006.

(48) Mallard, W.; Lindstrom, P. NIST Chemistry WebBook, NIST Standard Reference Database Number 69.

(49) Ribeiro Da Silva, M. D. M. C.; Ribeiro Da Silva, M. A. V.; Pilcher, G. Enthalpies of Combustion of 1,2-Dihydroxybenzene and of Six Alkylsubstituted 1,2Dihydroxybenzenes. The Journal of Chemical Thermodynamics 1984, 16, 11491155.

(50) Sabbah, R.; Buluku, E. N. L. E. Étude Thermodynamique Des Trois Isomères Du Dihydroxybenzène. Can. J. Chem. 1991, 69, 481-488.

(51) Luo, Y. R. Handbook of Bond Dissociation Energies in Organic Compounds; CRC Press: Boca Raton, 2003.

(52) Allara, D. L.; Shaw, R. A Compilation of Kinetic Parameters for the Thermal Degradation of $\mathrm{N}$-alkane Molecules. Journal of Physical and Chemical Reference Data 1980, 9, 523-560.

(53) Ingham, T.; Walker, R. W.; Woolford, R. E. Kinetic Parameters for the Initiation Reaction $\mathrm{RH}+\mathrm{O} 2 \rightarrow \mathrm{R}+\mathrm{HO} 2$. Symposium (International) on Combustion 1994, 25, 767-774.

(54) Pousse, E.; Tian, Z. Y.; Glaude, P. A.; Fournet, R.; Battin-Leclerc, F. A Lean Methane Premixed Laminar Flame Doped with Components of Diesel Fuel Part III: Indane and Comparison between n-Butylbenzene, n-Propylcyclohexane and Indane. Combustion and Flame 2010, 157, 1236-1260.

(55) Fittschen, C.; Delcroix, B.; Gomez, N.; Devolder, P. Rate Constants for the Reactions $\mathrm{OfCH} 3 \mathrm{O}$ with $\mathrm{CH} 2 \mathrm{O}, \mathrm{CH} 3 \mathrm{CHO}$ and i-C4H10. J. Chim. Phys. 1998, 95, 2129-2142.

(56) Buda, F.; Bounaceur, R.; Warth, V.; Glaude, P. A.; Fournet, R.; Battin-Leclerc, F. Progress toward a Unified Detailed Kinetic Model for the Autoignition of Alkanes from C4 to C10 between 600 and 1200 K. Combustion and flame 2005, 142, 170186.

(57) Tran, L. S.; Sirjean, B.; Glaude, P.-A.; Fournet, R.; Battin-Leclerc, F. Progress in Detailed Kinetic Modeling of the Combustion of Oxygenated Components of Biofuels. Energy 2012, 43, 4-18.

(58) Carstensen, H.-H.; Dean, A. M. A Quantitative Kinetic Analysis of CO Elimination from Phenoxy Radicals. Int. J. Chem. Kinet. 2012, 44, 75-89.

(59) da Silva, G.; Bozzelli, J. W. Benzoxyl Radical Decomposition Kinetics: Formation of Benzaldehyde $+\mathrm{H}$, Phenyl $+\mathrm{CH} 2 \mathrm{O}$, and Benzene $+\mathrm{HCO}$. J. Phys. Chem. A 2009, 113, 6979-6986.

(60) Altarawneh, M.; Dlugogorski, B. Z.; Kennedy, E. M.; Mackie, J. C. Thermochemical Properties and Decomposition Pathways of Three Isomeric Semiquinone Radicals. J. Phys. Chem. A 2010, 114, 1098-1108.

(61) Sirjean, B.; Fournet, R.; Glaude, P.-A.; Battin-Leclerc, F.; Wang, W.; Oehlschlaeger, M. A. Shock Tube and Chemical Kinetic Modeling Study of the Oxidation of 2,5-Dimethylfuran. Journal of Physical Chemistry A 2013, 117, 13711392. 
(62) Pecullan, M.; Brezinsky, K.; Glassman, I. Pyrolysis and Oxidation of Anisole near 1000 K. J. Phys. Chem. A 1997, 101, 3305-3316.

(63) Altarawneh, M.; Dlugogorski, B. Z.; Kennedy, E. M.; Mackie, J. C. Theoretical Study of Unimolecular Decomposition of Catechol. J. Phys. Chem. A 2010, 114, 1060-1067.

(64) Prendergast, M. B.; Kirk, B. B.; Savee, J. D.; Osborn, D. L.; Taatjes, C. A.; Masters, K.-S.; Blanksby, S. J.; Silva, G. da; Trevitt, A. J. Formation and Stability of Gas-Phase o-Benzoquinone from Oxidation of Ortho-Hydroxyphenyl: A Combined Neutral and Distonic Radical Study. Phys. Chem. Chem. Phys. 2016, 18, 4320-4332.

(65) Ormond, T. K.; Scheer, A. M.; Nimlos, M. R.; Robichaud, D. J.; Troy, T. P.; Ahmed, M.; Daily, J. W.; Nguyen, T. L.; Stanton, J. F.; Ellison, G. B. Pyrolysis of Cyclopentadienone: Mechanistic Insights from a Direct Measurement of Product Branching Ratios. J. Phys. Chem. A 2015, 119, 7222-7234.

(66) Meana-Pañeda, R.; Truhlar, D. G.; Fernández-Ramos, A. High-Level DirectDynamics Variational Transition State Theory Calculations Including Multidimensional Tunneling of the Thermal Rate Constants, Branching Ratios, and Kinetic Isotope Effects of the Hydrogen Abstraction Reactions from Methanol by Atomic Hydrogen. The Journal of Chemical Physics 2011, 134, 094302.

(67) Hippler, H.; Viskolcz, B. Addition Complex Formation s. Direct Abstraction in the $\mathrm{OH}+\mathrm{C} 2 \mathrm{H} 4$ Reaction. Phys. Chem. Chem. Phys. 2000, 2, 3591-3596.

(68) Glaude, P. A.; Battin-Leclerc, F.; Fournet, R.; Warth, V.; Côme, G. M.; Scacchi, G. Construction and Simplification of a Model for the Oxidation of Alkanes. Combustion and flame 2000, 122, 451-462.

(69) Scheer, A. M.; Mukarakate, C.; Robichaud, D. J.; Ellison, G. B.; Nimlos, M. R. Radical Chemistry in the Thermal Decomposition of Anisole and Deuterated Anisoles: An Investigation of Aromatic Growth. Journal of Physical Chemistry A 2010, 114, 9043-9056. 


\section{Table of Content}
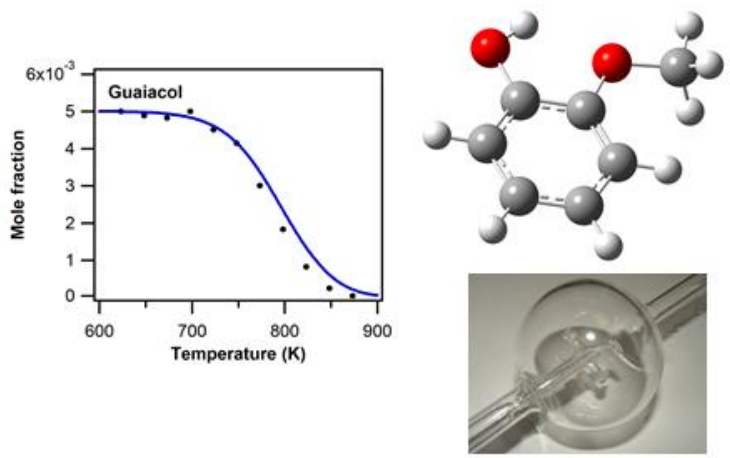